\title{
FALSE-COLOUR PHOTOGRAPHY: A NOVEL DIGITAL APPROACH TO VISUALIZE THE BEE VIEW OF FLOWERS
}

\author{
Christian Verhoeven ${ }^{1}$, Zong-Xin Ren ${ }^{2}$, and Klaus Lunau ${ }^{1}$ \\ ${ }^{1}$ Institute of Sensory Ecology, Department Biology, Heinrich-Heine-University Düsseldorf, Universitätsstr. 1, 40225 Düsseldorf, Germany \\ ${ }^{2}$ Key Laboratory for Plant Diversity and Biogeography of East Asia, Kunming Institute of Botany, Chinese Academy of Sciences, Kunming, \\ Yunnan 650201, People's Republic of China
}

\begin{abstract}
The colour vision system of bees and humans differs mainly in that, contrary to humans, bees are sensitive to ultraviolet light and insensitive to red light. The synopsis of a colour picture and a UV picture is inappropriate to illustrate the bee view of flowers, since the colour picture does not exclude red light. In this study false-colour pictures in bee view are assembled from digital photos taken through a UV, a blue, and a green filter matching the spectral sensitivity of the bees' photoreceptors. False-colour pictures demonstrate small-sized colour patterns in flowers, e.g. based on pollen grains, anthers, filamental hairs, and other tiny structures that are inaccessible to spectrophotometry. Moreover, false-colour pictures are suited to demonstrate flowers and floral parts that are conspicuous or inconspicuous to bees. False-colour pictures also direct the attention to other ranges of wavelength besides ultraviolet demonstrating for example blue and yellow bulls' eyes in addition to UV bulls' eyes which previously have been overlooked. False-colour photography is a robust method that can be used under field conditions, with various equipment and with simple colour editing.
\end{abstract}

Keywords: bee, colour vision, flower colour, colour pattern, bee view, false colour

\section{INTRODUCTION}

Flowers serve as filters signalling attractants for pollinators as well as deterrents for flower antagonists (Junker \& Blüthgen 2010). Due to differences in the number of photoreceptors types, the spectral range of sensitivity of the colour photoreceptors, and differences in the colour preference of various flower visitors, flowers can be attractive to pollinators and unattractive to illegitimate visitors, i.e. pollen thieves and nectar robbers, at the same time (Lunau \& Maier 1995; Lunau et al. 20II). Since many flower visitors, such as hummingbirds (Herrera et al. 2008), bats (Winter et al. 2003), bees (Peitsch et al. I992), hoverflies (Lunau 20I4), beetles (Martínez-Harms et al. 2012), butterflies and moths (Kelber et al. 2002; Arikawa 2003) are sensitive to ultraviolet light, these flower visitors necessarily view different aspects of the spectral reflectance of flowers as compared to UV-blind humans. Many of these flower visitors possess a different number of colour photoreceptor types compared to humans, e.g. one in bats, two in beetles, three in bees, four in hummingbirds and flies, and from three up to fifteen in butterflies (Briscoe 2008; Chen et al. 2016). This results in colour vision systems hardly conceivable to that in humans. However, bees have trichromatic colour vision just like humans, but are sensitive to ultraviolet, blue and green light rather than blue, green and red light as humans (Peitsch et al. 1992; Fig. I). Neuronal processing of colour photoreceptor

Received 22 January 2018, accepted 22 May 2018

*Corresponding author: Klaus.Lunau@hhu.de

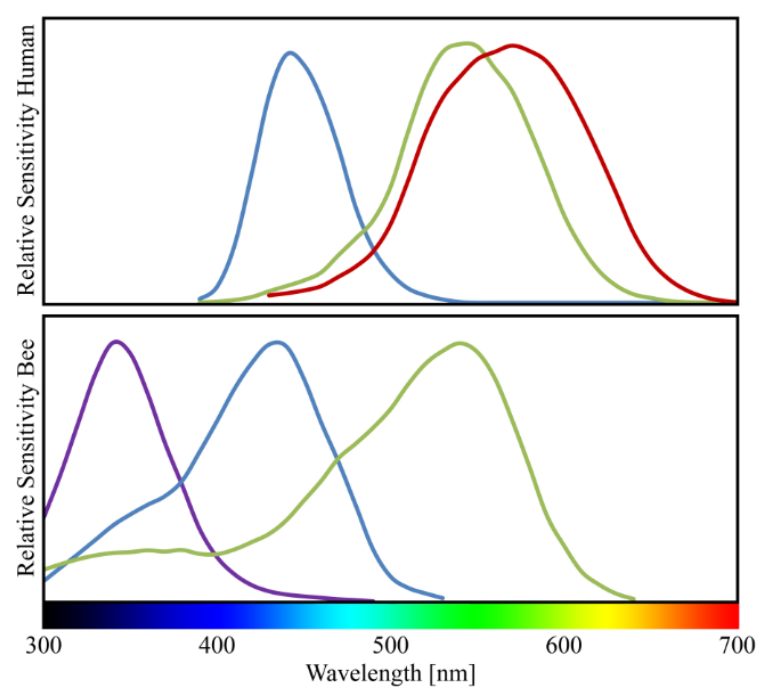

FIGURE I. Spectral sensitivity of colour photoreceptors. Top: Relative sensitivity of the three human photoreceptor types. The curves peak at $420 \mathrm{~nm}, 534 \mathrm{~nm}$ and $564 \mathrm{~nm}$ (Bowmaker et al. 1980). In the UV range of wavelength between $300 \mathrm{~nm}$ and $400 \mathrm{~nm}$ the photoreceptors are not sensitive (modified from Stockman et al. 1993). Bottom: Relative sensitivity of the three photoreceptor types of the honeybee (Apis mellifera). The curves peak at $344 \mathrm{~nm}, 436$ $\mathrm{nm}$ and $544 \mathrm{~nm}$. In the red range of wavelength between $630 \mathrm{~nm}$ and $700 \mathrm{~nm}$ (red light) the photoreceptors are not sensitive (modified from Peitsch et al. 1992).

inputs in bees and humans is similar, both bees and humans have colour opponent neurons (Backhaus I99I) and colour constancy (Neumeyer 198I). To understand flower colours and floral colours pattern as bees might see them Kevan 
(1978, 1979, 1983) claimed the need for a bee-subjective colorimetric analysis of flower colours.

Three methods are frequently used to study floral colours and colour patterns as perceived by bees. The measurement of the spectral reflectance by a spectrophotometer allows for the comparison of the spectral reflectance of a floral tissue with that of a black standard and of a white standard. A database provides access to spectral reflectance measurements for many plant species (Arnold et al. 2010). Reflection spectroscopy is limited by the size and surface properties of the measuring spot, which does not allow for measuring the reflectance of small-sized, curved or rough-textured structures like pollen grains, stamens, and filamental hairs. The standard method of reflection spectroscopy is a measurement angle of $45^{\circ}$ without integrating sphere (Chittka \& Kevan 2005; but see Stavenga $\&$ van der Kooi 2016). This method largely ignores the impact of the surface of petals being flat, conical or other, since most white standards possess a smooth if not glossy surface. Moreover, the transparency of the petals is ignored, since the flower, e.g. a petal, is placed on different backgrounds being black, white or another petal for measurements, which disregards light shining through the petal from the backside and the impact of the colour chosen as background.

Another method is the synopsis of a colour picture and a UV-picture showing the flower as appearing to humans and the ultraviolet reflection pattern on different pictures (Daumer 1958; Silberglied I979). This method possesses the disadvantage that the readers might be successful in notionally superimposing the colour picture and the UV-picture but fail to eliminate the red content of the colour picture at the same time. Red, however, is a component of yellow, magenta, purple and white colours. Moreover, the interpretation of UVpictures showing UV-absorbing parts of flowers is sometimes misleading, e.g. if it is concluded that red and UV-absorbing parts are invisible to bees (Chittka \& Waser 1997). A television camera equipped with UV-transmitting lens and UV-transmitting filter allowed direct observation and recording on video tape (Eisner et al. 1969; Silberglied 1976; Gronquist et al. 200I). Also, a modified image converter and image amplifier combined with UV-transmitting filter and UV-transmitting lens enabled to screen the UV-reflectance properties of many flowers (Rosen \& Barthlott I99I) in the field. However, classical UV-photography using a UVsensitive camera mounted on a tripod, UV-transmitting filter and UV-transmitting lens and a UV-sensitive film were still preferred to produce UV-photos with high quality (Biedinger \& Barthlott 1993; Burr \& Barthlott 1993; Burr et al. 1995; Lunau 2000). With the turn of the millennium, digital cameras were used mostly after having their internal UV- and IR-blocking filter removed and sometimes with the support of a UV-lamp for illumination (Koski \& Ashman 2013).

Several attempts have been made to develop methods to create colour pictures in bee view. As early as in 1958 Daumer tried to evaluate floral colours considering the bees' colour perception. He took photographs with a yellow, a blue and a UV filter and calculated the "bee-colour" (Daumer 1958), but of course he did not have the option to merge the photographs to a bee view-picture. Vorobyev et al. (I997) developed a method based on video recordings of flowers made by a UV-sensitive camera and specially selected set of filters to reconstruct images of flowers as bees might see them by calculating the quantum catches of the honeybee photoreceptors for each ommatidium dependent on the distance between bee and flower. Multispectral images, a series of black-and-white photos taken through different bandpass filters (Kevan 1972; Chittka and Kevan 2005) from alpine flowers of the Rocky Mountains, Colorado, are available from the Floral Image Database (http://liu.edu/flower). BenitezVieyra et al. (2007), Williams \& Dyer (2007), Brito et al. (2015) and Hempel de Ibarra et al. (2015) presented false colour photos of flowers in bee view, some of which require sophisticated calculations or calibrations. Photographic methods have also been used for simultaneous quantitative measurements of spatial and spectral components of floral colour patterns as seen by bees (Vorobyev et al. I997; BenitezVieyra et al. 2007; Williams \& Dyer 2007; Hempel de Ibarra \& Vorobyev 2009; Garcia et al. 20I4; Hempel de Ibarra et al. 2015; White et al. 2015).

Recent studies presenting multispectral images from flowers in bee view (Garcia et al. 20I4; Brito et al. 20I5; Hempel de Ibarra et al. 20I5; White et al. 2015; Vasas et al. 2017) are mostly focusing on one or few target species and /or require sophisticated calculations or calibrations. In this study we introduce a simple and cheap method for general use based on a slightly modified and supplemented standard camera equipment to create UV-pictures and false-colour pictures in bee view and to highlight the rationale of this method for field studies. The estimated prices for a low-cost and a standard equipment as used in this study are shown in Supplement SI. This equipment is much less expensive than custom-built multispectral cameras, e.g. Spectrocam Multispectral Wheel Cameras (Ocean Optics). The pictures are intended to demonstrate the bee-subjective colour patterns of flowers in bee view with details that cannot be measured using a normal spectrophotometer. Moreover, it is demonstrated how false-colour pictures in bee view are used to better understand the impact of the bees' sensitivity for ultraviolet and insensitivity for red light. For this purpose, false-colour pictures of floral colour changes and small-sized floral structures are shown as false-colour pictures. In addition, yet undescribed forms of colour patterns are described using false colour pictures such as blue bull's eyes rather than ultraviolet bull's eyes (Silberglied 1979; Koski \& Ashman 20I4). The robustness of this method is tested by the comparison of false-colour pictures taken with different cameras, lenses, filters, different picture editing programs and in field conditions.

\section{MATERIALS AND METHODS}

False-colour photography of flowers and floral colour patterns in bee view is an extension to the well-established UV-photography. The editing of digital pictures allows to split a colour picture into the colour channels and to reassemble a colour picture from the colour channels and thus to use a UV-channel instead of blue, a blue channel instead of green and a green channel instead of red in order to shift the range of wavelength for about $100 \mathrm{~nm}$. To match the bee photoreceptors' sensibility as close as possible specific filters 
might be used. Here the principal method of false-colour photography is described and the quality of results obtained with different equipment and with different processing is compared.

\section{Equipment}

To capture photos in bee view we used a modified Panasonic GH-I camera. The low-pass filter was removed in order to increase the sensitivity for ultraviolet light. We used an Ultra-Achromatic-Takumar I:4.5/85 lens made of fused quartz that transmits UV light. Since the modified camera is sensitive to ultraviolet and infrared light, we used a UV-/IRCut filter to capture a normal reference picture. This filter transmits light between $400 \mathrm{~nm}$ and $700 \mathrm{~nm}$ only (Fig. 2). To simulate the spectral sensitivity of typical bee photoreceptor types we used special filters that only transmit light of certain ranges of wavelengths (Fig. 3). Other equipment used included a Nikon D40 camera with low-pass filter, a 18-55 mm Nikkor lens and a 105 mm UV-Nikkor lens. In addition, only a UV picture and a colour photo split into the colour channels were used for picture processing (see below). A robust tripod and calm conditions are necessary for taking the different photos since changing the filter in between can be time-consuming. A white Teflon disc reflecting equal amounts of light in a range of wavelength from $300 \mathrm{~nm}$ to $700 \mathrm{~nm}$ was used for manual white balance before taking photos. Alternatively, a 20\% Spectralon Grey Standard was used (see below).

\section{Photography}

Since most flowers are small we set the aperture values between $\mathrm{f} / 8$ and $\mathrm{f} / \mathrm{I} 6$ to ensure good image resolution. The exposure time and ISO value of the camera were adjusted to the daylight. All pictures were focused manually because the viewfinder is completely dark after attaching the UV transmitting filter. Four photos were taken, one photo with UV-/IR-Cut filter, one photo with the UV filter, one photo with the blue, and one photo with the green filter. All pictures were saved in the camera's RAW format. This allows to adjust the white balance in post-production. As a reference we used a Spectralon Grey Standard that reflects all wavelengths of the needed $300 \mathrm{~nm}$ to $700 \mathrm{~nm}$ spectrum with $20 \%$. The grey

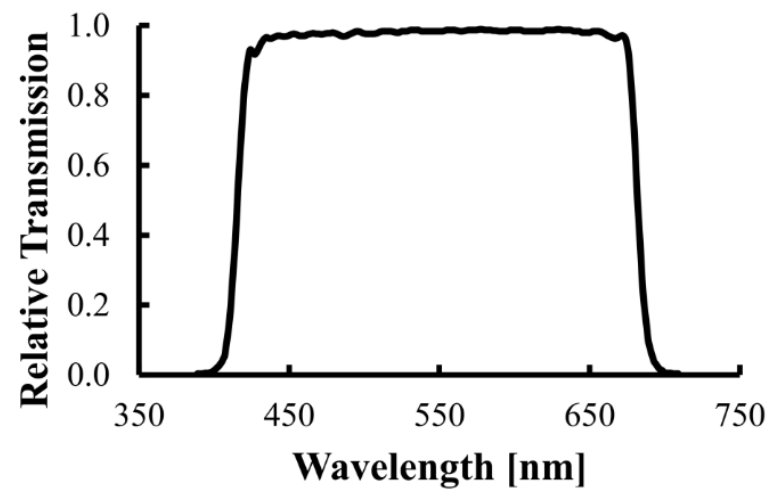

FIGURE 2. Relative transmission of the UV-/IR-Cut filter (Baader). Only light between $400 \mathrm{~nm}$ and $700 \mathrm{~nm}$ can transmit the filter (changed according to Baader Planetarium 2017).

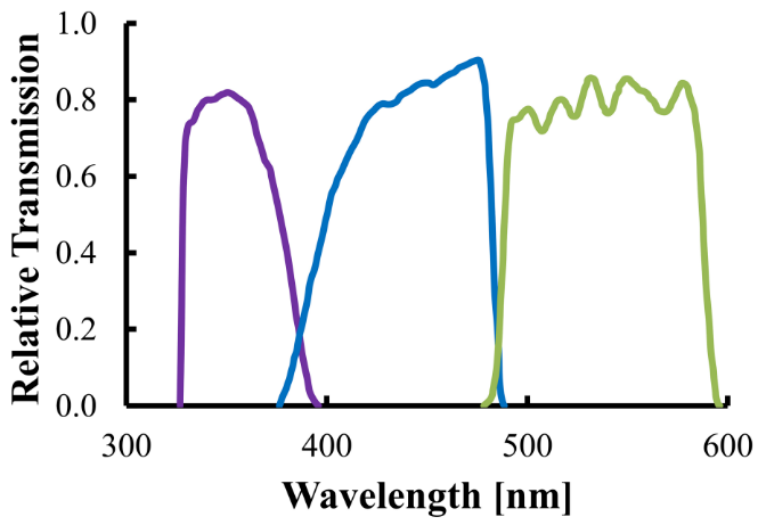

FIGURE 3. Relative transmission of the three colour filters (Baader). Violet: UV-filter transmits UV light only. Blue: Blue filter that only transmits blue light. Green: Green filter that only transmits light of the green part of the spectrum (changed according to Schmitt K., personal communication, 2I. September 2015).

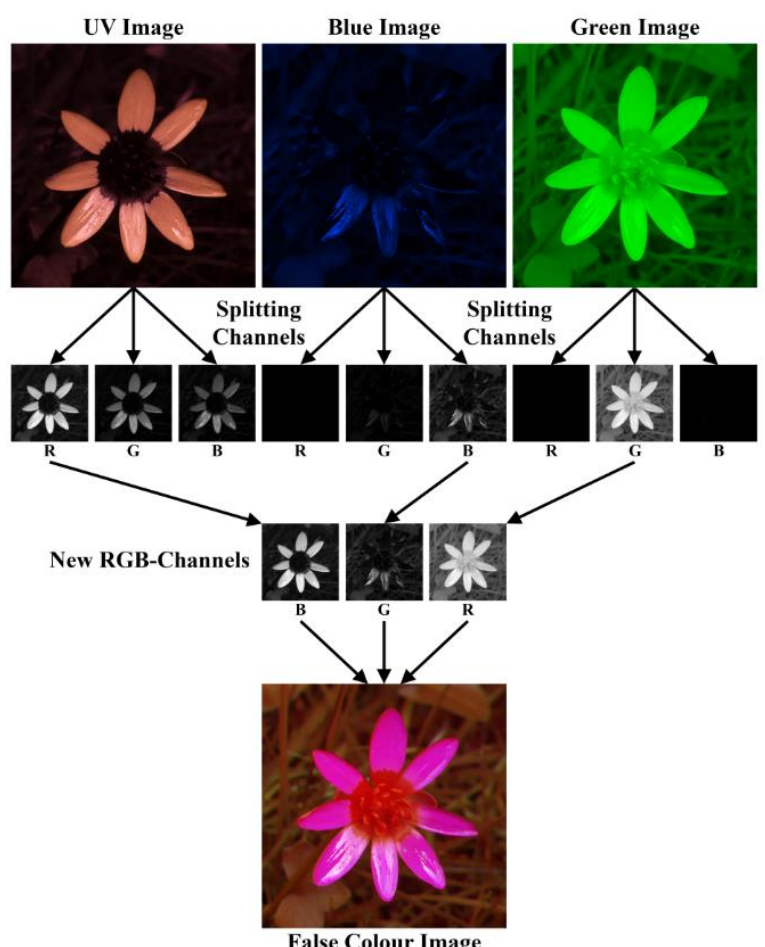

FIGURE 4. The splitting and merging process in detail.

reference was captured for every channel (normal, blue, green, UV) with the flowers or in separate pictures and always under the identical light and with identical camera settings.

\section{Picture editing}

The pictures taken with the UV, blue, and green filter were split into the colour channels in order to convert the merged picture into the RGB system which is visible for humans. From the picture with UV filter the red channel, from that with blue filter the blue channel, and from that with green filter the green channel was used for merging (Fig. 4). In windy conditions the frequent change of filters might not be useful. The alternative option is to take only two photos, one with the UV-/IR-Cut filter and one with the UV-filter. The photo taken with the UV-/IR-Cut filter then is split to 


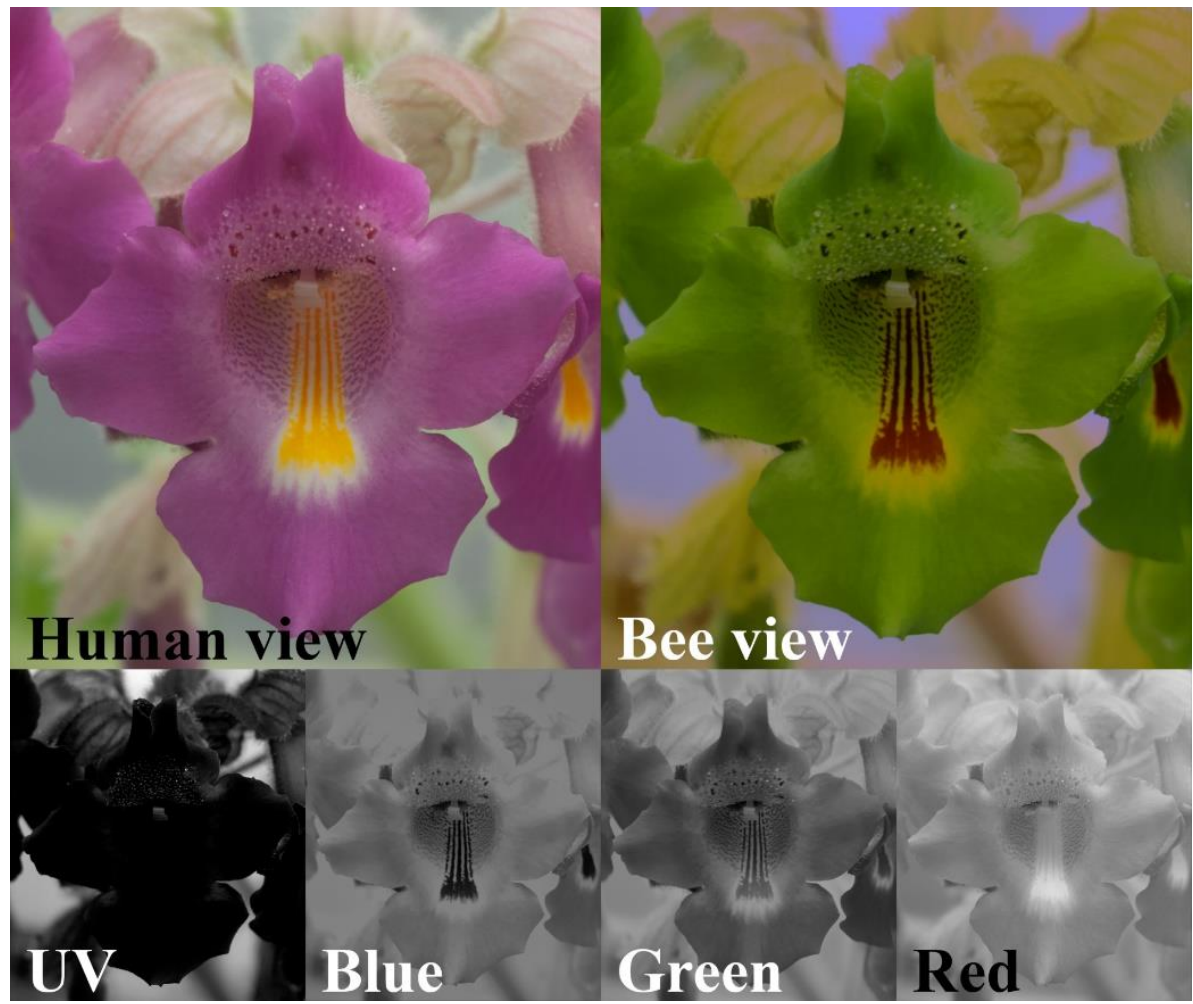

Figure 5. Colour picture of the ram's horn Proboscidea louisianica (Martyniaceae) showing the human view and false-colour picture showing the bee view. The merging of the false-colour picture was done using the UV, blue and green channel and by omitting the red channel.

the colour channels and the merging of the false-colour photo is done with the split colour photo and the split UV photo. To merge the channels to a bee view picture all captured pictures were pre-adjusted using Adobe Lightroom CC (version 2015 or newer). The merging was done in Photoshop or ImageJ. Moreover, preset white balance values can be used to reduce time between the two photos.

If only two photos were taken using manual white balance with a white and UV-reflecting Teflon disc, one photo was taken with UV-/IR-Cut filter and one with the UV-filter. Then the picture taken with the UV-/IR-Cut filter was split into the colour channels and the blue and green channels were used for merging. The red channel was discarded. Also, the photo taken with the UV-filter was split into the colour channels and the red channel was used for merging. In addition, we resigned the use of the RAW format or used a modified Nikon D40 camera and a plastic lens Nikon AF-S DX NIKKOR $18-55 \mathrm{~mm}$. The merging was done in Photoshop or ImageJ.

For producing false-colour pictures the UV channel was converted to the new blue channel, the blue channel to the green, and green channel to the new red channel (Fig. 5). To analyse the pictures the following colour translation chart is useful (Tab. I). For a picture that shows colours in bee view we need a UV, a blue and a green colour channel. These three colour channels need to be converted into the RGB system, which is visible for humans. Since the red channel is not needed it can be discarded. The bees' S-type of photoreceptors is sensitive for UV light. The humans' S-type of photoreceptors is sensitive for blue light. As a consequence, we convert the UV channel to the new blue channel, the blue channel is shown as green and green as red.

\section{Grey Standard}

All pictures were saved in the camera's RAW format. This allows to adjust the white balance in post-production. As a reference we used a Spectralon Grey Standard Labsphere SRS20-0I0 that reflects all wavelengths of the needed $300 \mathrm{~nm}$ to $700 \mathrm{~nm}$ spectrum with $20 \%$. The grey reference was captured for every photo, resp. channel (normal, blue, green, UV) with the flowers or in separate pictures and always under the identical light and with identical camera settings. To merge the channels to a bee view picture all captured pictures were pre-adjusted using Adobe Lightroom CC (version 2015 or newer).

\section{Preparing the pictures using Adobe Lightroom}

By using the histogram in Adobe Lightroom we adjusted the pictures so that the containing grey standard has the same brightness in all pictures. The histogram shows how many pixels in a picture ( $y$-axis) have a certain brightness ( $x$-axis). This is shown for the blue, the green and the red channel. Since we only use the blue channel of the picture captured with the blue filter, the brightness of the picture was adjusted so that the peak of the blue channel is exactly in the middle of the histogram (Fig. 6). We did the same with the peak of the green channel in the picture that was captured using the green filter. Because red channel of our cameras seems to be more UV sensitive than the other channels we adjusted the UV picture so that the peak of the red channel is in the middle of the histogram. In pictures where we captured the grey standard separately we adjusted the picture containing the grey standard and copied the values to the picture containing just the flower. 


\begin{tabular}{|l|l|l|l|}
\hline Real colour & Colour we see & Colour the bees see & $\begin{array}{l}\text { Colour we see in the } \\
\text { false-colour picture }\end{array}$ \\
\hline UV & Black & Bee-Ultraviolet & Blue \\
\hline Blue +UV & Blue & Bee-UV-Blue & Cyan \\
\hline Green +UV & Green & Bee-Purple & Purple \\
\hline Red +UV & Red & Bee-Ultraviolet & Blue \\
\hline Blue & Blue & Bee-Blue & Green \\
\hline Blue +Green & Cyan & Bee-Blue-Green & Yellow \\
\hline Blue +Red & Purple & Bee-Blue & Green \\
\hline Green & Green & Bee-Green & Red \\
\hline Green +Red & Yellow & Bee-Green & Red \\
\hline Red & Red & Bee-Black & Black \\
\hline White -UV & White & Bee-Blue-Green & Yellow \\
\hline White +UV & White & Bee-White & White \\
\hline Black -UV & Grey & Bee-Black & Black \\
\hline Black +UV & Bee-Ultraviolet & Blue \\
\hline Grey -UV & Bee-Blue-Green & Yellow \\
\hline Grey +UV & Bee-Grey & Grey \\
\hline
\end{tabular}

TABLE I. Colour Translation Chart

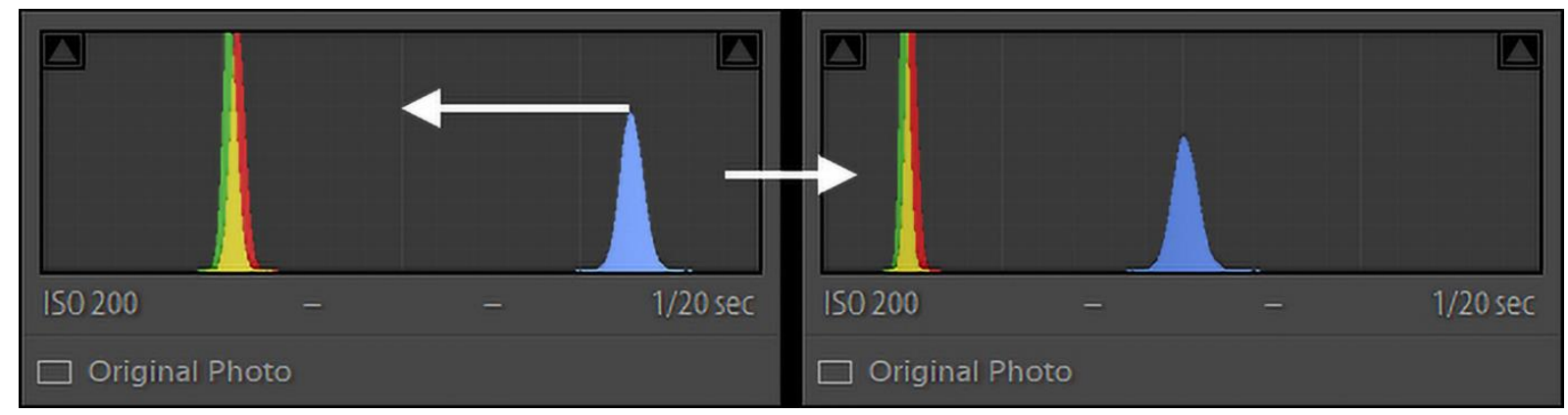

Figure 6. Histogram of a picture taken with the blue filter. On the left: Picture without adjustments. It is clearly visible that the blue channel of the picture is overexposed. On the right: The same picture after adjusting the brightness. The peak of the blue channel is now located in the middle and has the correct brightness.

For the normal picture we used the white balance dropper tool with the grey standard as a reference point to set the white balance.

\section{Merging the photos in Adobe Photoshop}

The prepared green, blue and UV pictures were opened in Photoshop as layers. At this point every picture still consists of three colour channels (RGB). By using the command "Image > Apply Image" we discarded the channels not needed. Figure 7 shows the settings that we used to discard the green and the red channel of the blue image/layer. This command overwrites the blue image with its own blue colour channel.

We used the same dialogue to overwrite the green image with its own green colour channel and to overwrite the UV image with its own red channel.

Using the command "Layer $>$ Layer Style $>$ Blending Options" we converted the layers into their new colour channels. Under "Advanced Blending" we unchecked the colour channels not needed. For example: The blue image 


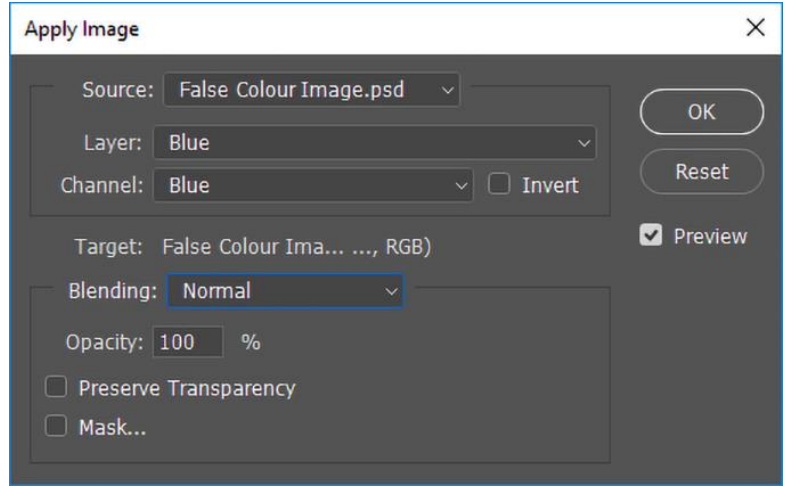

Figure 7: The "Apply Image" dialogue in Photoshop. The layer with the blue image gets overwritten with its own blue colour channel. The not needed green and red channels get discarded.

becomes the new green channel so we unchecked " $R$ " and "B" (Fig. 8).

In some cases, the images are a little bit shifted to one another. To compensate this, we re-aligned the images by clicking "Select $>$ All Layers" and "Edit > Auto-Align
Layers". We used the projection method "Reposition" or "Auto". If this method did not work we aligned the layers manually using the "Move Tool".

If the grey standard was photographed next to the flower it should be grey in the false-colour image as well. If it shows a colour tint the new created colour channels are not perfectly equally bright. These small colour shifts were corrected by using a "Levels Adjustment Layer". By creating a new empty layer in the uppermost position and using the shortcut "Ctrl + Alt + Shift + E" (on Windows) we merged the whole falsecolour picture to a single layer. With the "Marquee Tool" we selected the surface of grey standard and blurred the selected area with the command "Filter $>$ Blur $>$ Average". This ensures that the influence of the grainy structure of the standard and noise from the camera's sensor are as small as possible.

We created a "Levels Adjustment Layer" by clicking "Layer > New Adjustment Layer > Levels" in the uppermost position. By using the Tool "Sample in image to set grey point" on the blurred area this layer corrects all the colours in the image using the grey standard as a reference (Fig. 9).
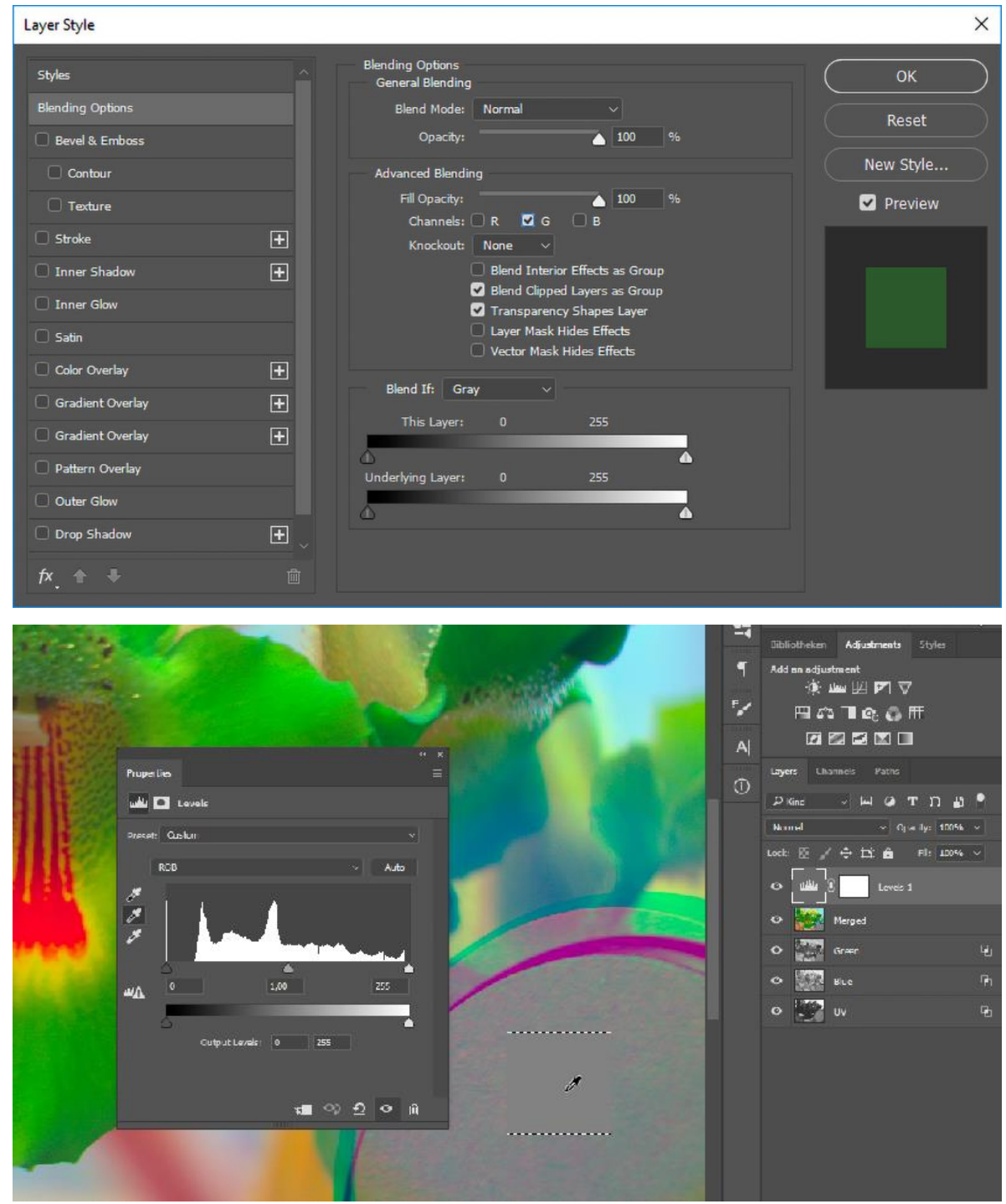

FigurE 8. The "Blending Options" dialogue in Photoshop. Under "Advanced Blending" we can decide to which colour channel the image/layer gets converted to. This figure shows the settings for the blue image/layer that gets converted to the new green channel.

FIgURE 9. Levels

Adjustment Layer. If the grey standard was photographed in separate pictures and not next to the flower we also converted these photos into a false-colour picture and followed all described steps. Then we copied the "Levels Adjustment Layer" to the falsecolour picture of the flower. The pictures were saved in the Photoshop PSD format and as JPGs (8 Bit, sRGB). 


\section{Merging the photos in ImageJ}

To verify the merging process and to show an alternative to Photoshop we also merged some images using ImageI and the plugin "MICA Toolbox" (Troscianko \& Stevens 2015).

Because we used special colour filters we had to create a custom *txt file that tells the program which colour channels from which image are getting used (Fig. I0). How this works shall not be explained in detail in this paper because there is a comprehensive user guide available on the programmer's website.

To merge the images, we opened Image command "Plugins $>$ Multispectral Imaging $>$ Generate Multispectral Image". In the upcoming dialogue we adjusted some settings. Under "Settings" we chose our custom ".txt file. All other settings are visible in Fig. I I.

After starting the process by clicking "OK" ImageJ automatically asks for the different pictures and guides the user through different steps that we followed. First, we opened the green image containing the grey standard and selected the standards surface area. Then the program asks for the green image without the standard. The steps repeat with the blue and the UV image. In between we manually aligned the images since we selected "Manual Align” (Fig. II).

When all images were opened and aligned we used the command "Plugins $>$ Multispectral Imaging $>$ Tools $>$ Make Presentation Image". In the following dialogue box, we decided that the green channel of the green image becomes the new red channel, the blue channel of the blue image becomes the new green channel and the red channel of the UV image becomes the new blue channel. We also chose "Square Root" under "Transform" and checked the "Convert to RGB colour" box (Fig. I2).

By clicking "OK" the program merges the images to a false-colour image. We saved the images as JPEG files.

\section{Interpretation of false-colour pictures}

In order to test the value of false-colour photography we studied floral colour changes and floral colour patterns and compared false-colour pictures and UV-pictures as a basis for the interpretation of the flower colours as seen by bees. A series of false-colour pictures of sub-alpine and alpine flowers were taken to test the reliability of this method. Whether the results of false-colour photography are similar with deviant equipment, deviant picture processing and different filters were also tested by using the selected flowers.

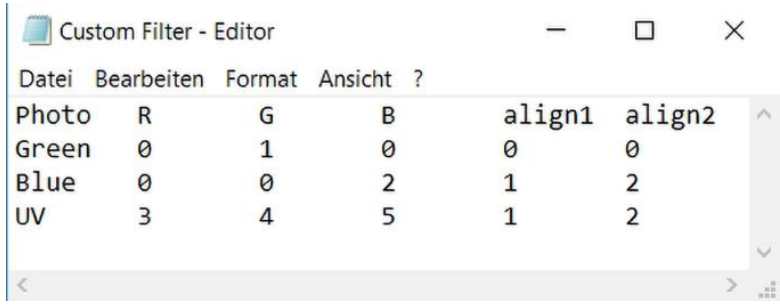

FigurE I0: The custom txt file created to tell the program which colour channel to use.

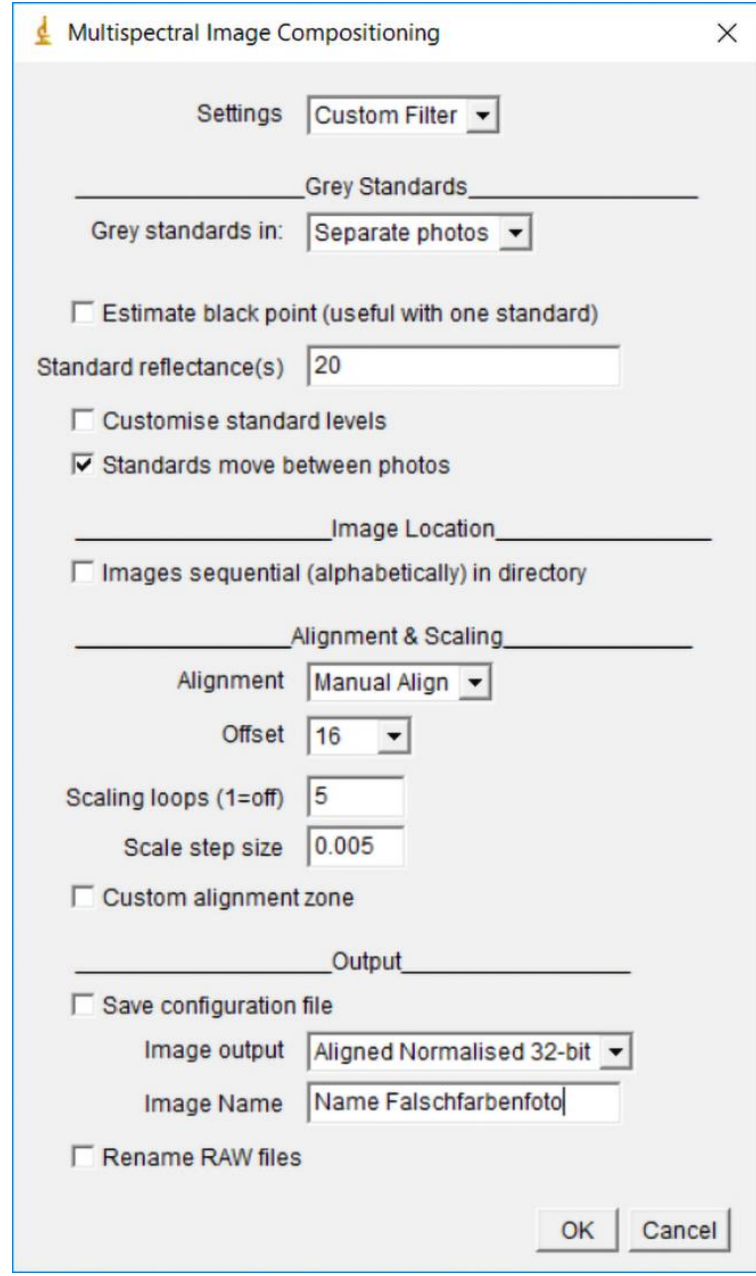

FIGURE II. The settings that were used to create a false-colour image with ImageJ. We told the program that the grey standard was captured in separate photos and that is moves between them. We also set the reflectance to $20 \%$. Under 'Alignment \& Scaling' we chose manual align. We set the output to 'Aligned Normalised 32-bit'.

\section{RESULTS}

\section{Colour change}

Floral colour changes in the Shrubby Milkwort Polygala chamaebuxus (Polygalaceae) affects the conspicuousness of the post-change colour in the false-colour picture but is not detectable in the ultraviolet range of wavelength (Fig. I3 A, B, C). The pre-change as well as the post-change colour of the Common Lungwort Pulmonaria officinale (Boraginaceae) are reflecting ultraviolet light and are conspicuous for bees according to the false-colour picture (Fig. I3 D, E, F). The Field Forget-me-not Myosotis arvensis (Boraginaceae) displays a yet undescribed threefold colour change. The purplish early flowing phase and middle bluish flowering phase display a colour change visible to the human eyes. But the flower petals also change from UV-absorbing to UVreflecting. This colour change is visible to bees' eyes but invisible to the human eyes. The colour change from the bluish and UV-absorbing middle flowering phase to the equally bluish late UV-reflecting flowering phase is visible to bees' eyes as is the colour change from human-yellow to human-white of the floral guide (Fig. I3 G, H, I). 


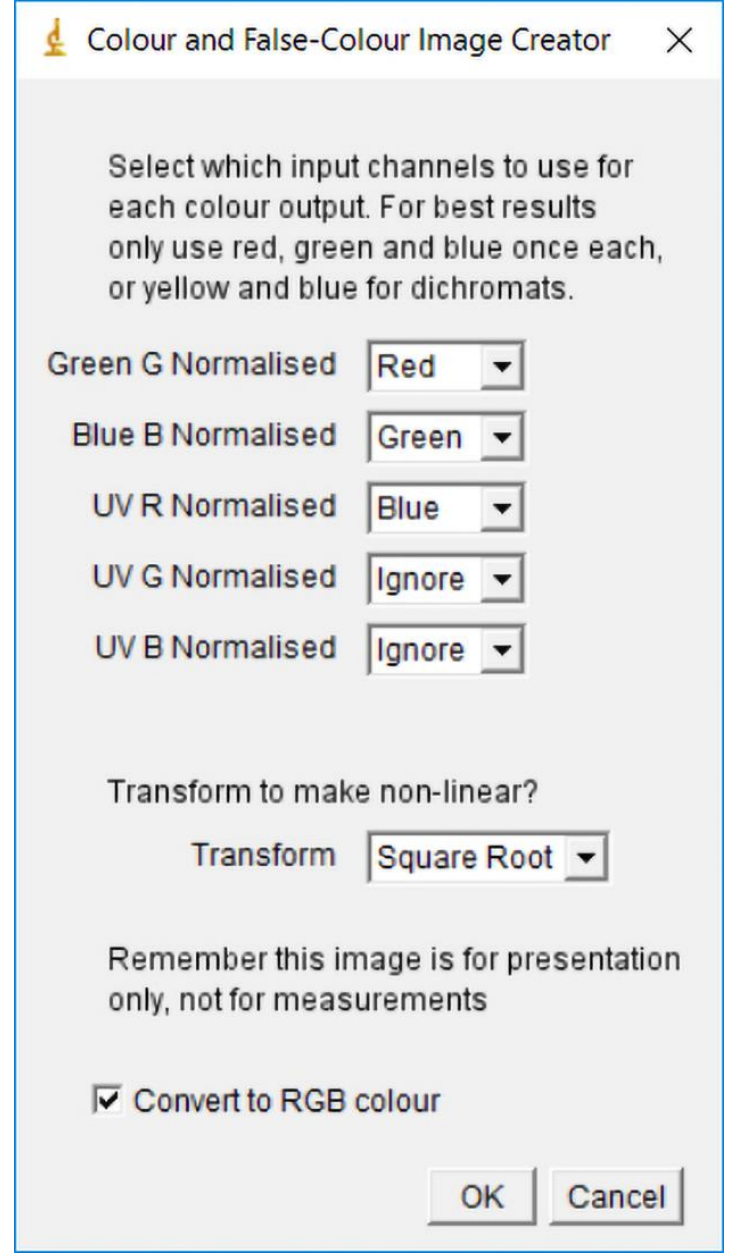

FIGURE I2. Dialogue box to select that the green channel from the picture taken with the green filter becomes the new red channel, blue channel from the picture taken with the blue filter becomes green and the red channel from the picture taken with the UV filter becomes blue.

\section{Bull's eyes}

Bull's eye refers to colour patterns that highlight the rewarding center of a flower. Some of these bull's eyes are visible to bees but invisible to humans (e. g. UV bull's eyes). Some colour patterns can be visible to humans too, but there are also non-UV colour patterns that are invisible to humans. The Yellow Archangel Lamium galeobdolon (Lamiacae) displays a typical all-yellow flower colour and an additional ultraviolet bull's eye resulting in a conspicuous colour pattern in bee view (Fig. I4 A, B, C). The flower displays two shades of yellow which are congruent with the UV-pattern (Fig. I4 A, B, C). The Marshmarigold Caltha palustris (Ranunculaceae) is uniformly yellow, but nevertheless displays a bee-visible colour pattern due to a pattern of reflection in the ultraviolet light (Fig. I4 D, E, F). The Yellow Daffodil Narcissus pseudonarcissus (Amaryllidaceae) shows no ultraviolet, but a blue bull's eye resulting in a colour pattern visible to bees (Fig. I5). The Key of Heaven Primula veris (Fig. I6 A, B, C) and the Oxlip Primula elatior (Fig. I6 D, E, F; Primulaceae) have all-yellow flowers, reflect uniform in the ultraviolet range of wavelength, but nevertheless display a colour pattern visible to bees. The Great Mullein Verbascum phlomoides (Scrophulariaceae) has all-yellow flowers and displays an ultraviolet bull's eye. Due to an additional blue bull's eye the floral colour pattern is rather complex in bee view (Fig. 17).

\section{Tiny structures}

False-colour pictures are able to display small-scale floral colour patterns visible to bees as shown for stamens and florets of the Cornflower Centaurea cyanus (Asteraceae) (Fig. I8 A, $\mathrm{B}, \mathrm{C})$ pollen and white staminal protuberances of the Flowerof-an-hour Hibiscus trionum (Malvaceae) (Fig. I8 D, E, F), a colour gradient of small-sized floral guides of the RoundLeaved Saxifrage Saxifraga rotundifolia (Saxifragaceae) (Fig. I8 G, H, I) and the androeceum of the Wood Anemone Anemone nemorosa (Ranunculaceae) (Fig. I8 J, K, L).

\section{Didactics}

The conspicuousness or inconspicuousness of human-red flowers for bees' eyes is dependent of the ultraviolet reflection as demonstrated for the UV-reflecting flower of the Winged Pea Lotus tetragonolobus (Fig. I9 A, B, C; Fabaceae) and the Red Poppy Papaver thoeas (Fig. I9 G, H, I; Papaveraceae) as well as the UV-absorbing flower of Forrests Rhododendron Rhododendron forrestii (Fig. I9 D, E, F; Ericaceae). The underside of the petals in the Lousewort Pedicularis gruina (Orobanchaceae) display a rare white and UV-reflecting colour (Fig. I9 J, K, L), whereas the white flowers Common Snowdrop Galanthus nivalis (Amaryllidaceae) stand out against the snow due to absorption of ultraviolet light (Fig. I9 M, N, O). The Bittersweet Nightshade Solanum dulcamara (Solanaceae) displays yellow anthers and green floral guides on the petals with possess a similar colour for bees (Fig. I9 P, Q, R).

Colour pattern of sub-alpine and alpine flowers on the mountains of eastern Himalayas

A series of photos taken under field conditions in the surroundings of the Lijiang Forest Ecosystem Research Station operated by the Kunming Institute of Botany, Chinese Academy of Sciences (China) using automatically controlled exposure to light for UV-photos and for colour photos, a single white balance value for all colour photos and another for all UV-photos and later manual adjustment of the brightness of the channels reveals satisfactory results (Fig. 20, 2I). This equipment was easily carried on an international flight and proved to stay functional at high altitude with low temperature, low oxygen and high UV-radiation. The Edelweiss flower of Leontopodium sp. (Asteraceae) possesses hairy petals inaccessible to spectrophotometry (Fig. 20 A, B, C). The white part of the fused dorsal petals of the Lousewort Pedicularis cephalantha (Orobanchaceae) displays a colour that is rarely found in bee-pollinated plants, i.e. a white and UV-reflecting colour (Fig. 20 D, E, F). The flower of Tibetia yunnanensis (Fabaceae) displays a white, yet UV-absorbing floral guide similar to pollen-mimicking floral guides described above (Fig. 20 G, H, I). The flower of Primula poissonii (Primulaceae) possesses no UV-pattern, yet a beevisible floral guide (Fig. $20 \mathrm{~J}, \mathrm{~K}, \mathrm{~L}$ ). The flower of Salvia hylocharis (Lamiaceae) displays an unusual type of floral guide absorbing all visible wavelengths as well as ultraviolet 

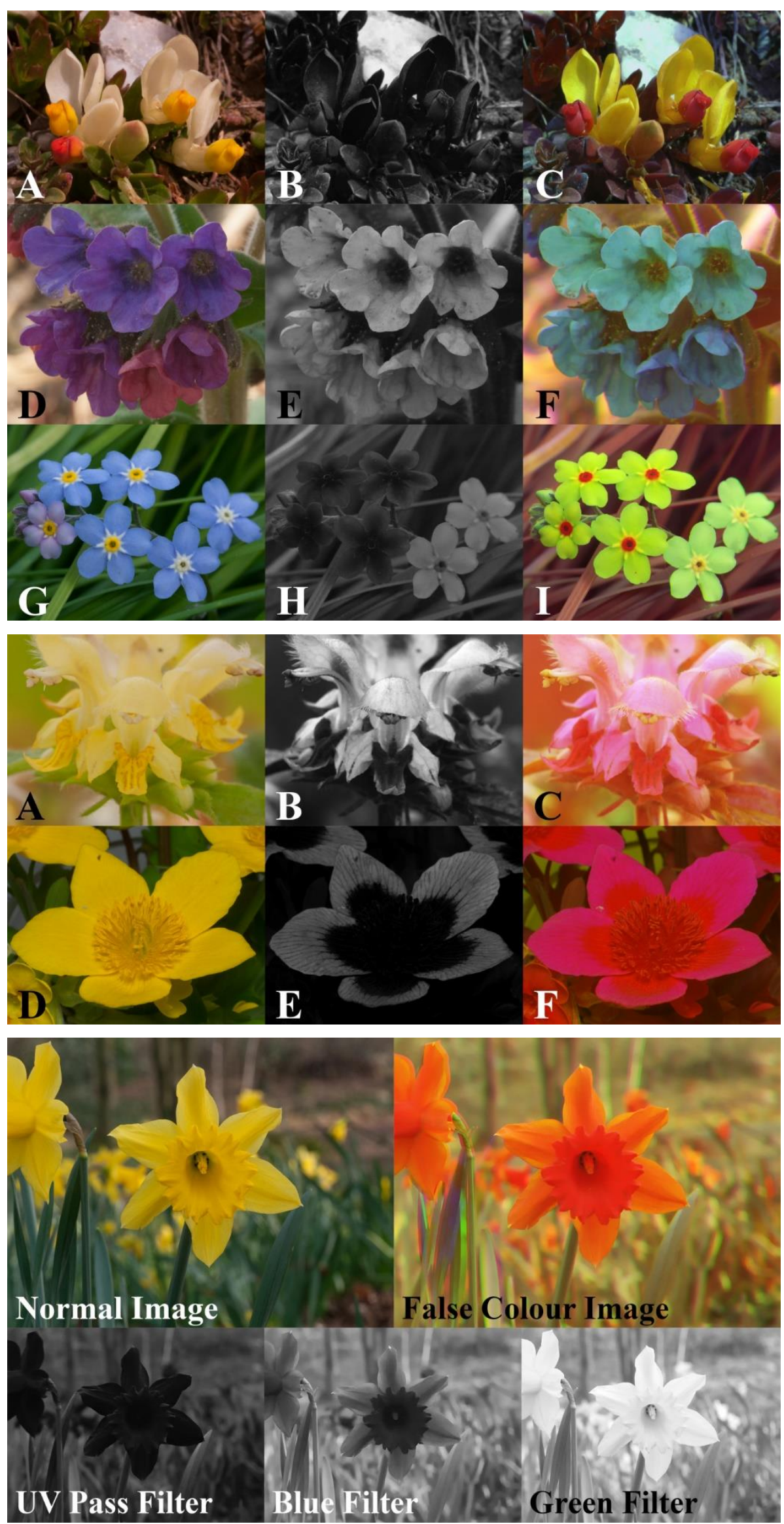

FIGURE I3. Colour pictures (left), UV-pictures (middle) and false-colour pictures (right) of floral colour change in Polygala chamaebuxus L. (A, B, C), Pulmonaria officinalis L. (D, E, F), and Myosotis arvensis Hill (G, H, I).

FIGURE I4. Colour pictures (left), UV-pictures (middle) and false-colour pictures (right) of bull's eyes in Lamium galeobdolon (L.) (A, B, C) and Caltha palustris L. (D, E, F).

FIGURE I5: Colour picture, UV-picture and false-colour picture of Narcissus pseudonarcissuss L.. Additional pictures show the blue channel and the green channel. 


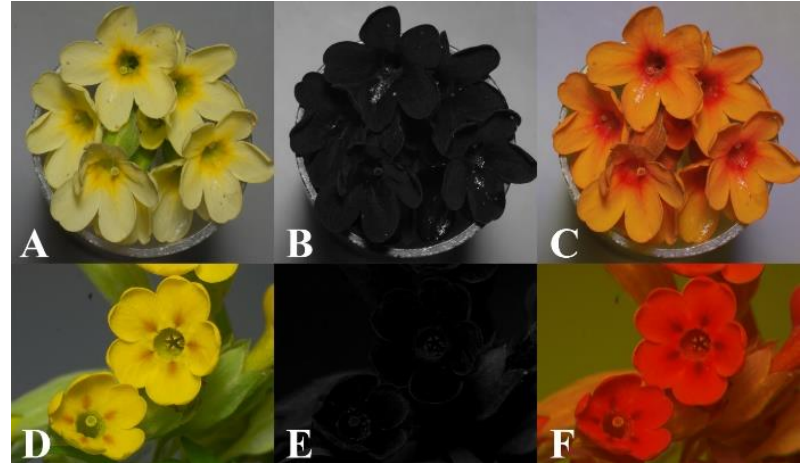

Figure I6. Colour pictures (left), UV-pictures (middle) and false-colour pictures (right) of Primula elatior (L.) (A, B, C) and Primula veris L. (D, E, F).

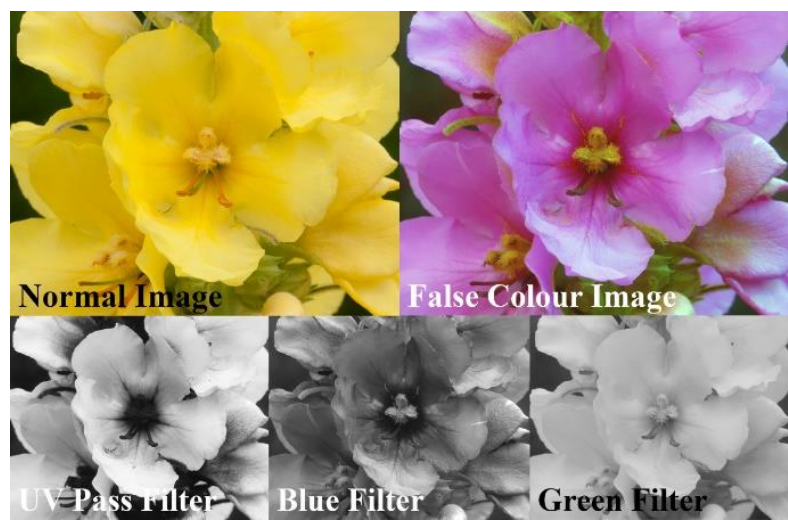

FIGURE 17. Colour picture, UV-picture and false-colour picture of Verbascum phlomoides L.. Additional pictures show the blue channel and the green channel.

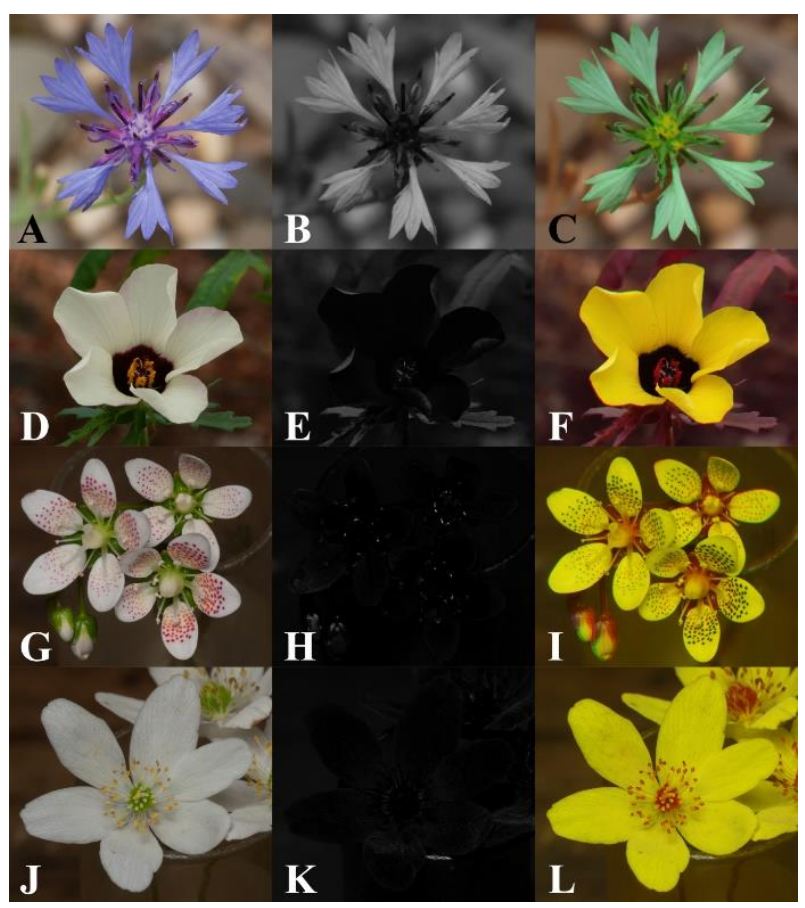

FIGURE I8: Colour pictures (left), UV-pictures (middle) and false-colour pictures (right) of Centaurea cyanus L. (A, B, C), Hibiscus trionum L. (D, E, F), Saxifraga rotundifolia L. (G, H, I) and Anemone nemorosa L. (J, K, L). light (Fig. 20 M, N, O). The pollinators of Paris polyphylla (Melanthiaceae) are still unknown (Ren et al. 20I4); although the flower displays no UV-pattern it has a bee-visible colour pattern (Fig. 20 P, Q, R). The Saxifrage Saxifraga signata (Saxifragaceae) possesses flowers with tiny yellow protuberances that uncommonly reflect ultraviolet light and might mimic the colour and gloss of nectar in addition to orange and UV-absorbing floral guides (Fig. 2I A, B, C). The yellow flower of Potentilla griffithii (Rosaceae) displays basal orange floral guides on each petal that are also visible to bees which, however, cannot be read from the UV-picture (Fig. 21 D, E, F). The yellow flower of the Lousewort Pedicularis longiflora (Orobanchaceae) displays two red floral guides which are invisible on the UV-picture, but clearly visible on the false-colour picture (Fig. 2I G, H, I). The flowers of the Lousewort Pedicularis tricolor (Fig. 2I J, K, L; Orobanchaceae) and of Trollius yunnanensis (Fig. 2I M, N $\mathrm{O}$; Ranunculaceae) display different shades of yellow and no UV-pattern which results in clearly bee visible colour pattern.

Robustness to changes in equipment and processing

We compared different false-colour images using the three colour filters with false-colour images that were taken with just the UV-/IR-Cut filter and the UV filter (Fig. $22 \mathrm{~A}$, B). The principal details about the colour change of Myosotis arvensis (Fig. I3, see above) are also found using deviant techniques. For the merging of the false-colour photos Adobe Photoshop (Fig. 22 C) and ImageJ (Fig. 22 D) were compared.

Using different cameras and lenses also revealed similar results; even the use of a cheap plastic lens with less transmittance of ultraviolet light than the quartz lenses seem adequate for creating false-colour pictures (Fig. 23).

To see if the method works without setting the white balance we created a false-colour picture without any brightness adjustments. The camera was set to auto (Fig. 24 A). We also used styrofoam as a reference standard to match the brightness levels in post (Fig. $24 \mathrm{C}$ ) to see if styrofoam can be a cheap alternative to grey standards. For reference we also took a false-colour image by using a spectralon grey standard and the described method (Fig. 24 D).

The result shows that the automatically exposed falsecolour picture without adjustments has a green colour cast (Fig. $24 \mathrm{~A}$ ). The camera overexposed the blue channel because the flower and the background don't reflect a lot of blue light. Because of the blue filter the camera sees a dark picture and tries to compensate by overexposing the picture. This leads to a green colour cast in the false-colour image (Fig. $24 \mathrm{~A}$ ). This problem can be solved by not using the blue and green filter and instead splitting the normal RGB image that were also taken by using the automatic exposure (Fig. 24 B). The resulting image looks similar to the false-colour picture taken with the grey reference standard (Fig. 24 D). This method however can still lead to colour casts since camera sees a dark picture through the UV filter and compensates by overexposing. 


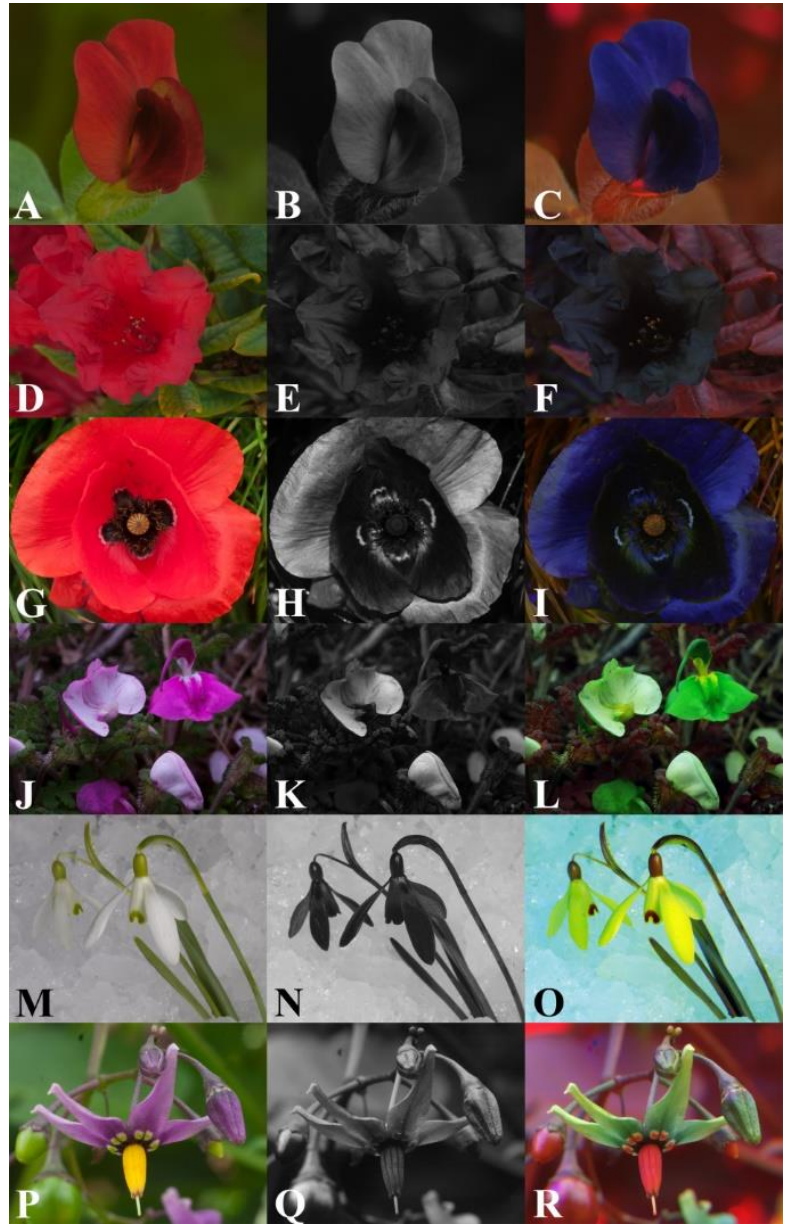

FIGURE 19. Colour pictures (left), UV-pictures (middle) and false-colour pictures (right) of Lotus tetragonolobus L. (A, B, C), Rhododendron forrestii B. Balfour ex Diels (D, E, F), Papaver thoeas L. (G, H, I), Pedicularis gruina Franch ex Maxim. (J, K, L), Galanthus nivalis $\mathrm{L} .(\mathrm{M}, \mathrm{N}, \mathrm{O})$ Solanum dulcamata L. (P, Q, R).

Using the styrofoam as a reference standard dramatically improves the results using the colour filters (Fig. 24 C). The false-colour image looks very similar to the false-colour picture taken with the grey reference standard (Fig. 24 D).

\section{DISCUSSION}

In this study a low-cost and easy-to-use multispectral imaging equipment is proposed and the advantages of false colour imaging over UV-photography and spectrophotometry are explained with some examples. Our equipment was proved to be effective to detect new floral color patterns and to be efficiently working in a high elevation mountain region in the Himalayas.

The equipment is configured for false colour photography in bee view. Bees use colour cues of flowers to find nectar and pollen sources (von Frisch 1915; Dyer at al. 20I4; Orban \& Plowright 2014). Experiments with honeybees and bumblebees have shown that flower visits consist of a series of behavioural reactions mostly based on visual cues. Initially bees are colour blind in their search for flowers in that they process only input to the green type of photoreceptors (Giurfa et al. 1996). Only if the visual angle viewing the target flower surpasses a threshold the bees use colour vision to find flowers
(Dyer et al. 2008). Naïve and inexperienced bees' innate colour preferences guide them towards promising flowers (Lunau \& Maier 1995; Lunau et al. 1996). Bees exhibit a preference for flowers displaying colour contrast against the background (Lunau et al. 1996), flower colours of high beesubjective saturation (Lunau et al. 1996), and prefer distinct colour hues, bee-subjective blue in the first place (Giurfa et al. 1995; Gumbert 2000; Milet-Pinheiro et al. 2015). When bees have approached a distinct flower, floral colour patterns are important for the flower to guide the bees towards a suitable site for the first physical contact with the flower by means of the antennae, landing (Lunau et al. 1996) and proboscis extension (Wilmsen et al. 2017). Floral colour patterns may include small-sized structures such as floral guides, veins, staminodes, stamens, anthers, filamental hairs and others (Lunau \& Wester 2017; Lunau et al. 2017). False colour images show flower colour patterns as seen by bees although the bee colours are visualized as human visible colours, UV as blue, blue as green and green as red (Kevan 1978, 1983; Kevan and Backhaus 1998). False colour images of flowers in bee view have been introduced several times (Kevan 1972; Vorobyev et al. I997; Chittka and Kevan 2005; Benitez-Vieyra et al. 2007; Williams \& Dyer 2007; Brito et al. 2015; Hempel de Ibarra et al. 2015). In this study, the

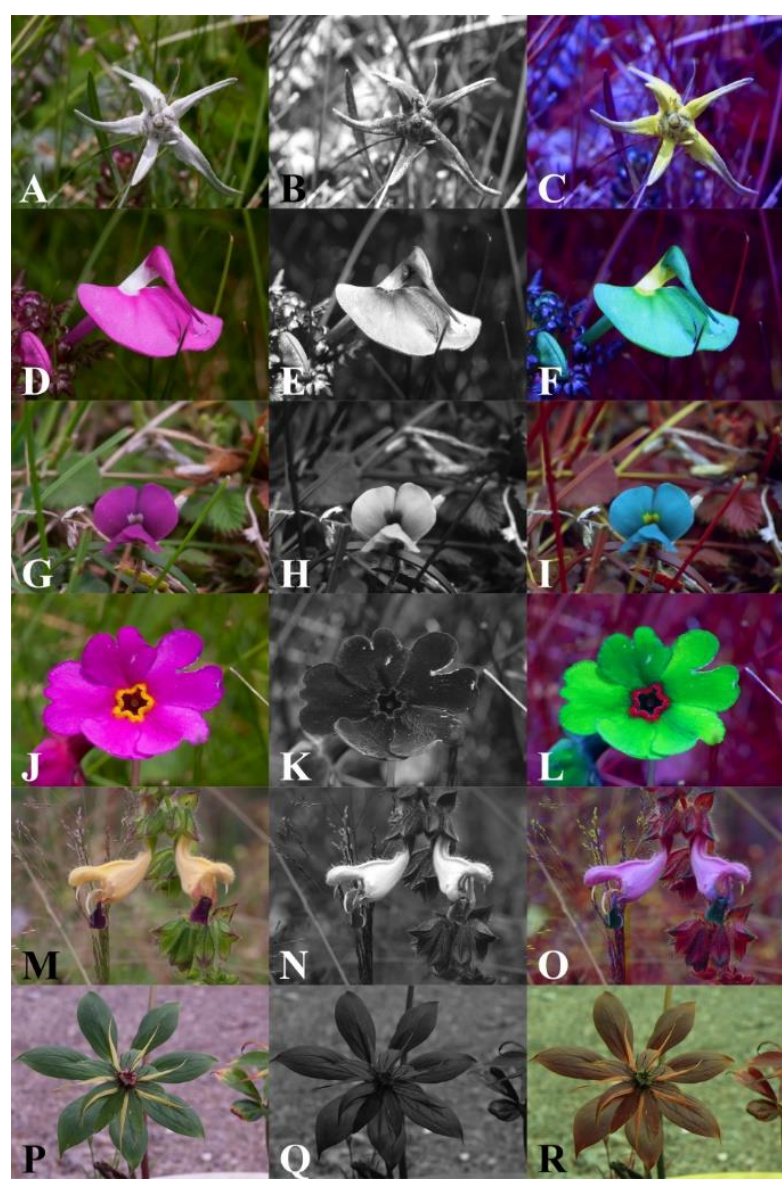

FIGURE 20. Colour pictures (left), UV-pictures (middle) and false-colour pictures (right) of flowers taken under field conditions in Lijiang (Yunnan, China). Leontopodium sp. (A, B, C), Pedicularis cephalantha Franch. ex Maxim. (D, E, F), Tibetia yunnanensis (Franch.) Tsui (G, H, I), Primula poissonii Franch. (J, K, L), Salvia hylocharis Diels $(\mathrm{M}, \mathrm{N}, \mathrm{O})$, Paris polyphylla var. yunnanensis (Franch.) Hand.-Mazz (P, Q, R). 


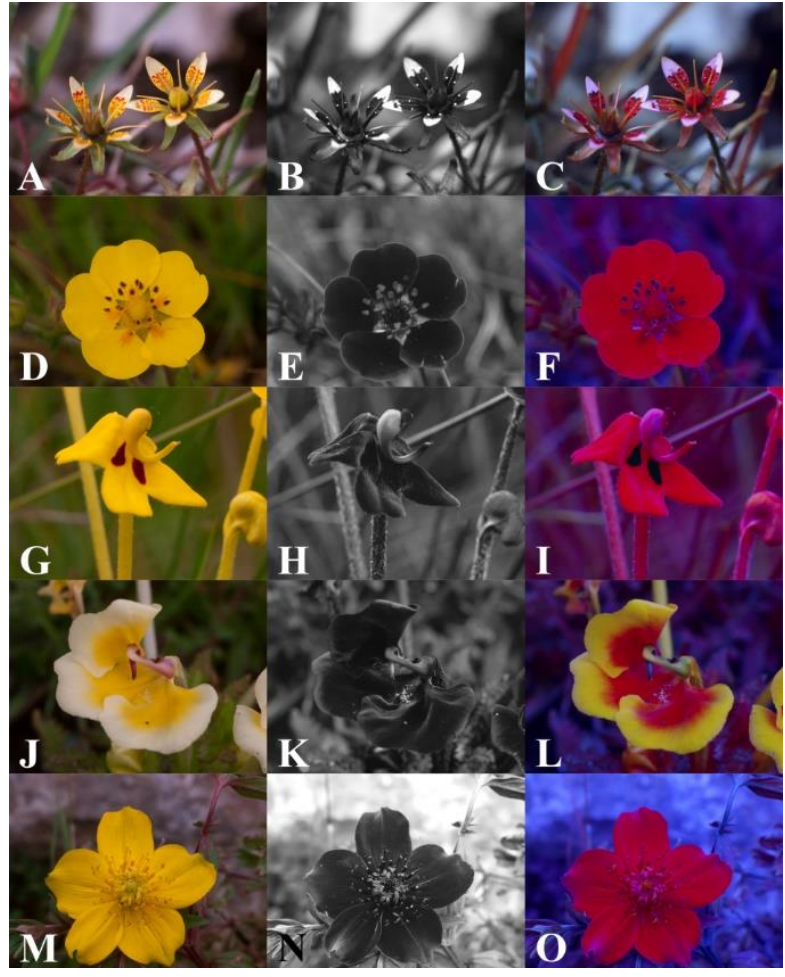

FIGURE 2I: Colour pictures (left), UV-pictures (middle) and false-colour pictures (right) of flowers taken under field conditions in Lijiang and Shangri-La (Yunnan, China). Saxifraga signata Engl. et Irmsch. (A, B, C), Potentilla griffithii var. velutina Card. (D, E, F), Pedicularis longiflora Rudolph (G, H, I), Pedicularis tricolor Hand.Mazz. (J, K, L), Trollius yunnanensis (Franch.) Ulbr. (M, N, O).

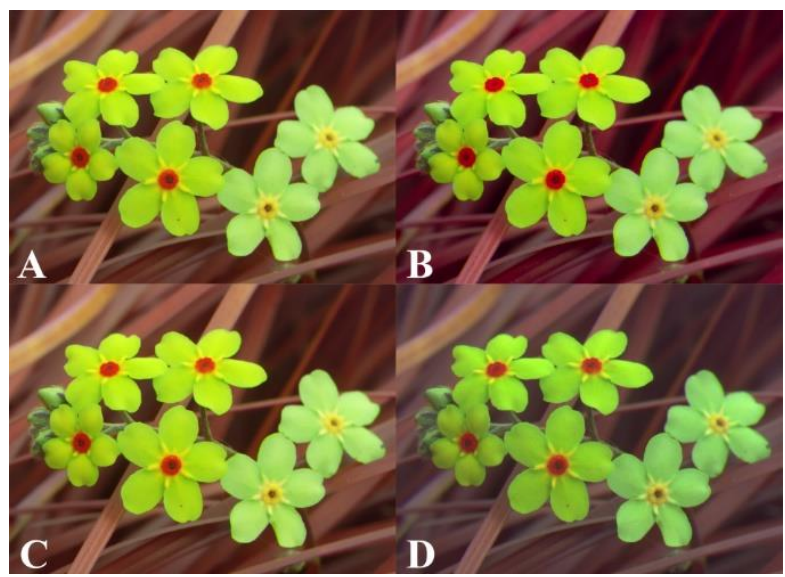

FIGURE 22. False-colour picture of Myosotis arvensis L. merged from photos taken with UV, blue and green filter (A), merged from photos taken with UV filter and the UV-/IR-Cut filter split into colour channels (B), Adobe Lightroom and Photoshop (C), and ImageJ and MICA Toolbox (D).

advantages of false colour imaging over UV-photography and spectrophotometry are clearly demonstrated by multiple examples, especially by the undetected colour pattern of subalpine and alpine flora on the high mountain of eastern Himalayas in China.

Interpreting flowers as seen by bees requires the consideration of ultraviolet and bee-visible ranges of wavelength (Kevan 1978, 1979, 1983), although ultraviolet reflections in general are not more important than blue or green ones (Kevan et al. 200I). Rarely the bees' lower sensitivity in the red range of wavelength has brought into focus (Cure \& Wittmann 1990; Chittka \& Waser I997; Lunau et al. 20I I; Bergamo et al. 2016). The fact that bees are red blind or less sensitive to red light has caused lot of confusion about how bees might perceive red colours (Hinton 1976; Johnson \& Midgley 200I; Rodríguez-Gironés \& Santamaría 2004; Martínez-Harms et al. 2010). It was found that some bees have developed sensitivity in the red range of wavelength (Cure \& Wittmann I990; Chittka \& Waser 1997) or the red colour of flowers is used to exclude bee as potentially nectar-robbing flower visitors (Lunau et al. 20I I Bergamo et al. 2016), since bees see red colours without additional reflection in the UV as black. Sensory exclusion of bees was also proposed for white, UV-reflecting birdpollinated flowers, since UV-reflecting white colours are not spontaneously preferred by bees (Lunau et al. 1996; 201 I). In the Lousewort Pedicularis gruina a similar phenomenon is demonstrated for the buds of the violet flowers which display the white, UV-reflecting underside of the petals. The Snowdrop Galanthus nivalis represents the common type of white bee-pollinated flowers (Kevan et al. 1996). In the Red Poppy Papaver thoeas (Papaveraceae) the red flowers in the Eastern Mediterranean are pollinated by red sensitive glaphyrid beetles (Martínez-Harms et al. 2012), whereas the flowers in the Western part of Europe have evolved reflection in the red range of wavelength are pollinated by bees (Burkhardt 1997).

Floral colour change is known as a semi-honest indicator of floral nectar reward (Lunau \& Wester 2017). The fact that the flowering phase offering reward is attributed with a more attractive colour (Lunau 1996) is nicely demonstrated with the false-colour picture of Myosotis arvensis. In the Lungwort both the pre-change as well as the post-change flower colour seem to be attractive to bees (Oberrath \& Böhning-Gaese 1999) which is supported by false-colour pictures of a related Pulmonaria species. However, false-colour pictures might reveal yet unknown details of floral colour changes (Weiss $\&$ Lamont 1997; Ohashi et al. 2015). The bee view might be enhanced if the optical resolution is also considered (Rodríguez-Gironés \& Ruiz 2016; Lunau \& Verhoeven 2017).

One typical pattern is the so-called ultraviolet bull's eye (Silberglied 1979; Schlangen et al. 2009; Koski \& Ashman 20I4) of all-yellow flowers displaying a UV-reflecting periphery and a UV-absorbing center part either by pollen, anthers of pollen-mimicking floral guides (Lunau 2000, 2007; Lunau et al. 2017). In this study an all-yellow flower displaying a blue bull's eye as well as all-yellow flowers displaying a bee-visible colour pattern with different shades of yellow were found. It is known that the centre part of floral colour pattern directs the bees' approaches towards the first physical contact and landing site of flowers due to higher colour saturation and colour contrast against the corolla (Lunau et al. 1996; Papiorek et al. 2013; Wilmsen et al. 2017). In many cases the ultraviolet picture does not indicate the higher salience of the flowers' centre part rather than the false-colour picture. Even the absence of UV-reflection pattern is of significance for flower visitors, e.g. for yellow bird-pollinated flowers (Papiorek et al. 2013), and for yellow 


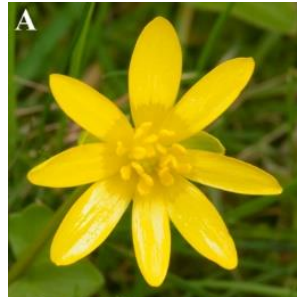

GH-1 \& 85mm Takumar

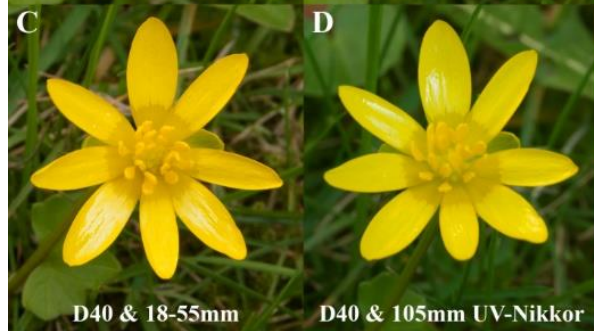

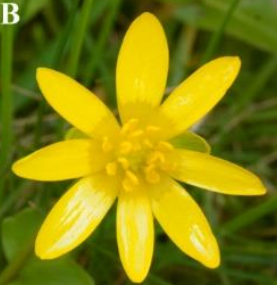

GH-1 \& $105 \mathrm{~mm}$ UV-Nikkor

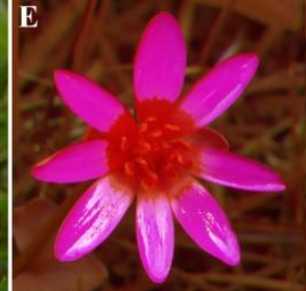

GH-1 \& 85mm Takumar

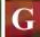

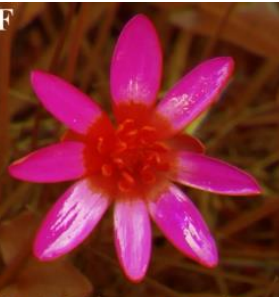

GH-1 \& 105mm UV-Nikkor

H

FigurE 23. Colour pictures (A-D) and false-colour pictures (E-H) of the Pilewort Ficaria verna L. (Ranunculaceae) taken with different camera equipment which was Panasonic GH-I camera and Pentax $85 \mathrm{~mm}$ Ultra Achromatic Takumar lens (A, E), Panasonic GH-I camera and IO5 mm UVNikkor lens (B, F), Nikon D40 camera and I8-55 mm Nikkor lens (C,G), and Nikon D40 camera and I05 mm UV-Nikkor lens (D, H).

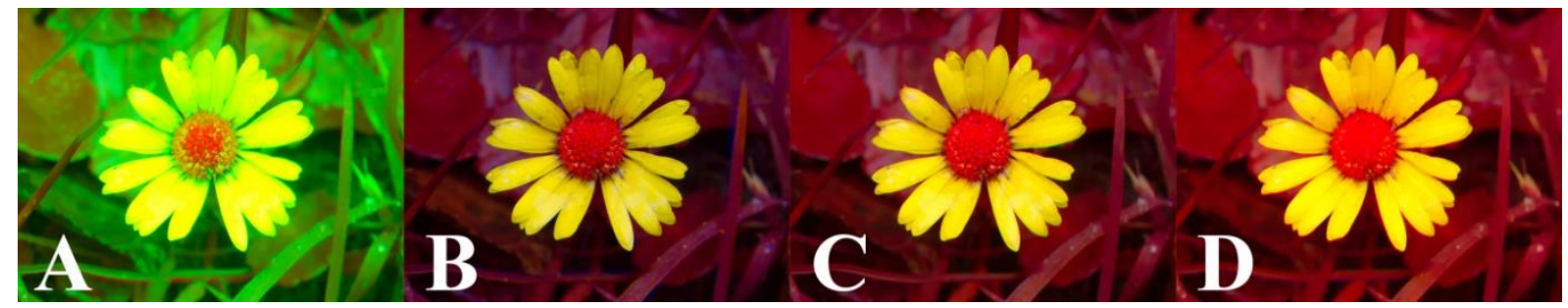

FIGURE 24: Bellis perennis A: False-colour picture taken with the camera set to auto and using the colour filters. The picture was assembled without any adjustments. B: False-colour picture taken with the camera set to auto. The picture was assembled without any adjustments and by splitting the RGB image. C: Before merging the pictures to the false-colour picture the brightness of the pictures were adjusted so that the styrofoam has the exact same brightness in every colour channel (white balance). D: False-colour image assembled by using the spectralon grey reference standard.

Crocus species (Lunau et al. 2016). A common type of colour pattern in all-yellow flowers is the combination of an orange floral guide with a yellow periphery without any UVpattern like in the California Poppy Eschscholzia californica (Papaveraceae) and Common Toadflax Linaria vulgaris (Plantaginaceae). It is still an open question whether and how this colour pattern is able to direct flower visitors towards the centre part of the flower (Lunau I992). If the spectral reflectance in the ultraviolet and blue ranges of wavelengths are negligible the orange colour might appear darker to the bees than the yellow colour and thus appear more beesubjective saturated, since darker colours appear at least to humans more saturated than lighter colours of similar chroma (Lübbe 2010).

The false-colour images will be helpful for plantpollinator interaction studies in these underexplored regions, such as Himalayas. We demonstrated the diversity of floral colours on the high elevation mountains in Lijiang and Shangri-La, eastern Himalayas. These flowers of the Chinese flora reveal a large diversity of bee-visible colour pattern which has not yet been described to our knowledge despite high intensity of studies in visual aspects of pollination biology in China (Shi et al. 2009; Eaton et al. 2012; Huang et al. 2015;
Ma et al. 2015; Zhang et al. 2017; Tao et al. 2018; Yan et al. 2018). Unusual flower colour patterns were detected in the bumblebee buzz-pollinated genus Pedicularis and indicated a highly diverse signal system in this genus. On the mountains of southwestern China, Pedicularis species exhibit a spectacular level of endemism and floral diversity $(>300$ species; Yang et al. 1998). The different Pedicularis species are pollinated by the same bumblebee species, but the floral mechanisms that ensure pollen deposits and pickups on different parts of the pollinator's body ("Pedicularis-type" of mechanical isolation) were well characterized in a few coexisting species in China (Wang \& Li 2005; Tong \& Huang 2016, 2018; Liang et al. 2018). However, the visual and olfactory signal aspects of this model system have not been explored yet.

The flora of China is extremely diverse with more than 30,000 species of angiosperms ( $\mathrm{Wu}$ et al. 2013). The mountains of southwest China are regarded as one of global hotspots of biodiversity with the highest diversity of species and endemism of all temperate floras (Myers et al. 2000). The floral diversity of high elevation mountains of this region is strongly shaped by generalist bee species, such as Chinese native honeybee Apis cerana and bumblebees (Ren et al. 20I4; 
Zhao et al. 2016). This region harbours the half of global species of bumblebees (Williams et al. 2009). The limited number of false-colour photos presented in this study indicate that the diverse bee pollination system in Himalayas requires more researches on their visual signals in the future. Our lowcost and easy-to-use multispectral imaging equipment will be helpful for the future when we explore these understudied areas.

In conclusion, this study shows that false colour images of flowers in bee view provide similar information as classical UV-photos and additional information about the floral colour pattern that is not available from UV-photos. The false colour images of flowers are easy to interpret due to the consistent bathochromic shift for about I0Onm during the reassembling to the false colour image resulting that all kinds of bee-visible colour patterns are seen as patterns rather than uniform colours. This also holds for very tiny structure like pollen grains, anthers, filamental hairs, and veins which is advantageous compared to spectrophotometry.

\section{APPENDICES}

Additional supporting information may be found in the online version of this article:

APPENDIX I. Estimated costs for a low-budget version and an optimal equipment for false colour photography in bee view.

\section{REFERENCES}

Arikawa K (2003) Spectral organization of the eye of a butterfly, Papilio. Journal of Comparative Physiology A I89:79I-800.

Arnold SEJ, Faruq S, Savolainen V, McOwan PW, Chittka L (2010) FReD: The Floral Reflectance Database - A web portal for analyses of flower colour. PLoS ONE 5(I2): eI4287.

Backhaus W (199I) Color opponent coding in the visual system of the honeybee. Vision Research 31:I38I-I397.

Benitez-Vieyra S, Hempel de Ibarra N, Wertlen AM, Cocucci AA (2007) How to look like a mallow: evidence of floral mimicry between Turneraceae and Malvaceae. Proceedings of the Royal Society B Biological Sciences 274:2239-2248.

Bergamo PJ, Rech AR, Brito VLG, Sazima M (2016) Flower colour and visitation rates of Costus arabicus support the "bee avoidance" hypothesis for red-reflecting hummingbird-pollinated flowers. Functional Ecology 30:710-720.

Biedinger N, Barthlott W (1993) Untersuchungen zur Ultraviolettreflexion von Angiospermenblüten. I Monocotyledonae. Tropische und Subtropische Pflanzenwelt 86:I-I22.

Bowmaker JK, Dartnall HJ (1980) Visual pigments of rods and cones in a human retina. The Journal of Physiology 298:50I-5I I.

Briscoe AD (2008) Reconstructing the ancestral butterfly eye: focus on the opsins. Journal of Experimental Biology 2I I:I805-18I3.

Brito VLG, Weynans K, Sazima M, Lunau K (2015) Trees as huge flowers and flowers as oversized floral guides: the role of floral color change and retention of old flowers in Tibouchina pulchra. Frontiers in Plant Science 6:362.

Burkhardt D (1997) Die Welt mit anderen Augen-Wie Insekten und Vögel die Welt und ihre Farben sehen. Biologie in unserer Zeit 19:37-46.

Burr B, Barthlott W (1993) Untersuchungen zur Ultraviolettreflexion von Angiospermenblüten II. Magnoliidae,
Ranunculidae, Hamamelididae, Caryophyllidae, Rosidae. Tropische und Subtropische Pflanzenwelt 87:I-193.

Burr B, Rosen D, Barthlott W (1995) Untersuchungen zur Ultraviolettreflexion von Angiospermenblüten III. Dilleniidae und Asteridae s.1.. Tropische und Subtropische Pflanzenwelt 93:I-I85.

Chen P-J, Awata H, Matsushita A, Yang E-C, Arikawa K (2016) Extreme spectral richness in the eye of the Common Bluebottle Butterfly, Graphium sarpedon. Frontiers in Ecology and Evolution $4: 18$.

Chittka L, Kevan PG (2005) Flower colour as advertisement. In: Dafni A, Kevan PG, Husband BC (eds) Practical Pollination Biology. Enviroquest Ltd., Cambridge, ON, Canada, pp I57-I96.

Chittka L, Menzel R (1992) The evolutionary adaptation of flower colors and the insect pollinators' color vision systems. Journal of Comparative Physiology A I7I:I7I-I8I.

Chittka L, Shmida A, Troje N, Menzel R (1994) Ultraviolet as a component of flower reflections, and the colour perception of Hymenoptera. Vision Research 34:1489-I508.

Chittka L, Waser NM (1997). Why red flowers are not invisible for bees. Israel Journal of Plant Sciences 45:169-I83.

Clark C (1979) Ultraviolet absorption by flowers of the Eschscholzioideae (Papaveraceae). Madrono 26:22-25.

Cure JR, Wittmann D (1990) Callonychium petuniae, a new panurgine bee species (Apoidea, Andrenidae) oligolectic on Petunia (Solanaceae). Studies on Neotropical Fauna \& Environment 25:I53-I56.

Daumer, K (1958) Blumenfarben, wie sie die Bienen sehen. Zeitschrift für vergleichende Physiologie 4I:49-IIO.

Dyer AG, Boyd-Gerny S, Mcloughlin S, Rosa MGP, Simonov V, Wong BBM (2012) Parallel evolution of angiosperm colour signals: common evolutionary pressures linked to hymenopteran vision. Proceedings of the Royal Society B: Biological Sciences 279:3606-36I5.

Dyer AG, Spaethe J, Prack S (2008) Comparative psychophysics of bumblebee and honeybee colour discrimination and object detection. Journal of Comparative Physiology A 194:617-627.

Eaton DAR, Fenster CB, Hereford J, Huang SQ, Ree RH (20I2) Floral diversity and community structure in Pedicularis (Orobanchaceae). Ecology 93:182-194.

Eisner T, Silberglied RE, Aneshansley D, Carrel JE, Howland HC (I969) Ultraviolet video-viewing: the television camera as an insect eye. Science I66:I172-I174.

Garcia JE, Greentree AD, Shrestha M, Dorin A, Dyer AG (20I4) Flower colours through the lens: Quantitative measurement with visible and ultraviolet digital photography. PLoS ONE 9(5):e96646.

Giurfa M, Núñez J, Chittka L, Menzel R (1995) Colour preferences of flower-naive honeybees. Journal of Comparative Physiology A 177:247-259.

Giurfa M, Vorobyev M, Kevan P, Menzel R (1996) Detection of coloured stimuli by honeybees: minimum visual angles and receptor specific contrasts. Journal of Comparative Physiology A 178:699709.

Gronquist M, Bezzerides A, Attygalle A, Meinwald J, Eisner M, Eisner T (200I) Attractive and defensive functions of the ultraviolet pigments of a flower (Hypericum calycinum). Proceedings of the National Academy of Sciences USA 98:13745I3750.

Guldberg LD, Atsatt PR (1975) Frequency of reflection and absorption of ultraviolet light in flowering plants. The American Midland Naturalist 93:35-43. 
Gumbert A (2000) Color choices by bumble bees (Bombus terrestris): innate preferences and generalization after learning. Behavioral Ecology and Sociobiology 48:36-43.

He Q, Shen Y, Wang M, Huang M, Yang R, Zhu S, Wang L, Wu $\mathrm{R}$ (20II) Natural variation in petal color in Lycoris longituba revealed by anthocyanin components. PLoS ONE 6(8): e22098.

Hempel de Ibarra N, Langridge KV, Vorobyev M (2015) More than colour attraction: behavioural functions of flower patterns. Current Opinion in Insect Science 12:64e70.

Hempel de Ibarra N, Vorobyev M (2009) Flower patterns are adapted for detection by bees. Journal of Comparative Physiology A 195:319-323.

Herrera G, Zagal JC, Diaz M, Fernández MJ Vielma A, Cure M, Martinez J, Bozinovic F, Palacios AG (2008) Spectral sensitivities of photoreceptors and their role in colour discrimination in the green-backed firecrown hummingbird (Sephanoides sephaniodes). Journal of Comparative Physiology A 194:785-794.

Hinton HE (1976) Possible significance of the red patches of the female crab-spider, Misumena vatia. Journal of Zoology I80:3539.

Huang Y, Li N, Ren ZX, Chen G, Wu ZK, Ma YP (2015) Reproductive biology of Primula beesiana (Primulaceae), an alpine species endemic to Southwest China. Plant Ecology and Evolution I48:289-296.

Johnson SD, Midgley JJ. (200I) Pollination by monkey beetles (Scarabaeidae: Hopliini): do colour and dark centres of flowers influence alighting behavior? Environmental Entomology 30:86I868.

Junker RR, Blüthgen N (2010) Floral scents repel facultative flower visitors, but attract obligate ones. Annals of Botany 105:777-782.

Kevan PG, Chittka L, Dyer AG (200I) Limits to the salience of ultraviolet: Lessons from color vision in bees and birds. Journal of Experimental Biology 204:257I-2580.

Kelber A, Balkenius A, Warrant EJ (2002) Scotopic colour vision in nocturnal hawkmoths. Nature 419:922-925.

Kevan PG (1972) Floral colors in the high arctic with reference to insect-flower relations and pollination. Canadian Journal of Botany 50:2289-23I6.

Kevan PG (1978) Floral coloration, its colorimetric and significance in anthecology. In: Richards AJ (ed.) The pollination of flowers by Insects. Linnean Society Symposium Series Vol. 6:5I-78.

Kevan PG (1979) Vegetation and floral colours revealed by ultraviolet light: interpretational difficulties for functional significance. American Journal of Botany 66:749-75I.

Kevan P (1983) Floral colours through the insect eye: what they are and what they mean. In: Jones CE, Little RJ (eds.) Handbook of Experimental Pollination Biology. Van Nostrand Reinhold, New York, pp 3-30.

Kevan PG, Backhaus WG (I998) Color vision: ecology and evolution in making the best of the photic environment. In Backhaus W, Kliegl R, Werner J (eds.) Color vision: perspectives from different disciplines. Walter de Gruyter, Berlin, pp I63-I83.

Kevan PG, Chittka L, Dyer AG (200I) Limits to the salience of ultraviolet: lessons from colour vision in bees and birds. Journal of Experimental Biology 204:257I-2580

Kevan P G, Giurfa M, Chittka L (1996) Why are there so many and so few white flowers? Trends in Plant Sciences I:280-284.

Koski MH, Ashman TL (2013) Quantitative variation, heritability, and trait correlations for ultraviolet floral traits in Argentina anserina (Rosaceae): implications for floral evolution. International Journal of Plant Sciences I74:I I09-I I20.
Koski MH, Ashman TL (20I4) Dissecting pollinator responses to a ubiquitous ultraviolet floral pattern in the wild. Functional Ecology 28:868-877.

Koski MH, Ashman TL (2015a). Floral pigmentation patterns provide an example of Gloger's rule in plants. Nature Plants I:I4007.

Koski MH, Ashman TL (2015b) An altitudinal cline in UV floral pattern corresponds with a behavioral change of a generalist pollinator assemblage. Ecology 96:3343-3353.

Liang H, Ren ZX, Tao ZB, Bernhardt B, Li DZ, Wang H. (2018) Impact of pre- and post-pollination barriers on pollen transfer and reproductive isolation among three sympatric Pedicularis (Orobanchaceae) species. Plant Biology; DOI:IO.I I I I /plb.I2833

Lübbe E (2010) Colours in the Mind - Colour Systems in Reality A formula for colour saturation. [Book on Demand].

Lunau K (1992) Innate recognition of flowers by bumblebees orientation of antennae to visual stamen signals. Canadian Journal of Zoology 70:2139-2I44.

Lunau K (1995) Notes on the colour of pollen. Plant Systematics and Evolution 198:235-252.

Lunau K (1996) Unidirectionality of floral colour changes. Plant Systematics and Evolution 200:125-I40.

Lunau K (2000) The ecology and evolution of visual pollen signals. Plant Systematics and Evolution 222:89-I I I.

Lunau K (2007) Stamens and mimic stamens as components of floral colour patterns. Botanische Jahrbücher für Systematik, Pflanzengeschichte und Pflanzengeographie I27:13-4I.

Lunau K (20I4) Visual ecology of flies with particular reference to colour vision and colour preferences. Journal of Comparative Physiology A 200:497-5I2.

Lunau K, Konzmann S, Bossems J, Harpke D (2016) A matter of contrast: Yellow flower colour constrains style length in Crocus species. PLoS ONE II(4):e0I54728.

Lunau K, Konzmann S, Winter L, Kamphausen V, Ren ZX (2017) Pollen and stamen mimicry: the alpine flora as a case study. Arthropod-Plant Interactions I I:427-447.

Lunau K, Maier EJ (1995) Innate colour preferences of flower visitors. Journal of Comparative Physiology A I77:I-I9.

Lunau K, Papiorek S, Eltz T, Sazima M (201I) Avoidance of achromatic colours by bees provides a private niche for hummingbirds. Journal of Experimental Biology 2I4:I607-I6I2.

Lunau K, Verhoeven C (2017) Wie Bienen Blumen sehen Falschfarbenaufnahmen von Blüten. Biologie in unserer Zeit 47:120-I27.

Lunau K, Wacht S, Chittka L (1996) Colour choices of naive bumble bees and their implications for colour perception. Journal of Comparative Physiology A 178:477-489.

Lunau K, Wester P (2017) Mimicry and deception in pollination. In: Becard G (ed.) Advances in Botanical Research, Vol. 82, How Plants Communicate with their Biotic Environment; pp 259-279, Academic Press, Amsterdam.

Ma XK, Shi J, Bänziger H, Sun YN, Guo YY, Liu ZJ, Johnson SD, Luo YB (2015) The functional significance of complex floral colour pattern in a food-deceptive orchid. Functional Ecology 30:72I-732.

Martínez-Harms J, Palacios AG, Márquez N, Estay P, Arroyo MTK, Mpodozis J (2010) Can red flowers be conspicuous to bees? Bombus dahlbomii and South American temperate forest flowers as a case in point. Journal of Experimental Biology 213:564-57I.

Martínez-Harms J, Vorobyev M, Schorn J, Shmida A, Keasar T, Homberg U, Schmeling F, Menzel R (2012) Evidence of red sensitive photoreceptors in Pygopleurus istaelitus (Glaphyridae: 
Coleoptera) and its implications for beetle pollination in the southeast Mediterranean. Journal of Comparative Physiology A I98:45I-463

Medel R, Botto-Mahan C, Kalin-Arroyo M (2003) Pollinator mediated selection on the nectar guide phenotype in the Andean monkeyflower, Mimulus luteus. Ecology 84:172I-1732.

Milet-Pinheiro P, Ayasse M, Dötterl S (2015) Visual and olfactory floral cues of Campanula (Campanulaceae) and their significance for host recognition by an oligolectic bee pollinator. PLoS ONE IO(6):e0I28577.

Myers N, Mittermeier RA, Mittermeier CG, da Fonseca GAB, Kent J (2000) Biodiversity hotspots for conservation priorities. Nature 403:853-858

Neumeyer C (198I) Chromatic adaptation in the honey bee: Successive color contrast and color constancy. Journal of Comparative Physiology I44:543-553.

Oberrath R, Böhning-Gaese K (1999) Floral color change and the attraction of insect pollinators in lungwort (Pulmonaria collina). Oecologia I2I:383-39I.

Ohashi K, Makino TT, Arikawa K (2015) Floral colour change in the eyes of pollinators: testing possible constraints and correlated evolution. Functional Ecology 29:I I44-I I55.

Orbán LL, Plowright CMS (20I4) Getting to the start line: how bumblebees and honeybees are visually guided towards their first floral contact. Insectes Sociaux 61:325-336.

Papiorek S, Junker RR, Alves-dos-Santos I, Melo GAR, AmaralNeto LP , Sazima M, Wolowski M, Freitas L, Lunau K (2016) Bees, birds and yellow flowers: Pollinator-dependent convergent evolution of UV-patterns. Plant Biology I8:46-55.

Peitsch D, Fietz A, Hertel H, de Souza J, Ventura DF, Menzel R (1992) The spectral input systems of hymenopteran insects and their receptor-based colour vision. Journal of Comparative Physiology A, 170:23-40.

Peterson ML, Miller TJ, Kay KM (2015) An ultraviolet floral polymorphism associated with life history drives pollinator discrimination in Mimulus guttatus. American Journal of Botany 102:396-406.

Primack RB (1982) Ultraviolet patterns in flowers, or flowers as viewed by insects. Arnoldia 42: I39-I46.

Ren ZX, Wang H, Bernhardt P, Li DZ (20I4) Insect pollination and self-incompatibility in edible and/or medicinal crops in southwestern China, a global hotspot of biodiversity. American Journal of Botany I0I:1700-I710.

Rodríguez-Gironés MA, Ruiz A (2016) toBeeView: A program for simulating the retinal picture of visual scenes on nonhuman eyes. Ecology and Evolution 6:7892-7900.

Rodríguez-Gironés MA, Santamaría L (2004) Why are so many bird flowers red? PLoS Biology 2(10):e350.

Rosen D, Barthlott W (I99I) Ökologische Aspekte der Ultraviolett-Reflexion von Blumen in Mitteleuropa, besonders in der Eifel. Decheniana I44:72-II2.

Schlangen K, Miosic S, Castro A, Freudmann K, Luczkiewicz M, Vitzthum F, Schwab W, Gamsjäger S, Musso M, Halbwirth H (2009) Formation of UV-honey guides in Rudbeckia hirta. Phytochemistry 70:889-898.

Shi J, Luo YB, Bernhardt P, Ran JC, Liu ZJ, Zhou Q (2009) Pollination by deceit in Paphiopedilum barbigerum (Orchidaceae): a staminode exploits the innate colour preferences of hoverflies (Syrphidae). Plant Biology II:17-28.

Silberglied RE (1976) Visualization and recording of longwave ultraviolet reflection from natural objects. Functional Photography II:20-29; 30-33.
Silberglied RE (1979) Communication in the ultraviolet. Annual Review of Ecology and Systematics 10:373-398.

Stavenga DG, van der Kooi CJ (2016) Coloration of the Chilean Bellflower, Nolana paradoxa, interpreted with a scattering and absorbing layer stack model. Planta 243:17I-I8I.

Stockman A, Macleod D, Johnson N (1993) Spectral sensitivities of the human cones. Journal of the Optical Society of America I0:249I-252I.

Tao ZB, Ren ZX, Bernhardt P, Liang H, Li HD, Zhao YH, Wang H, Li DZ (2018) Does reproductive isolation reflect the segregation of color forms in the Spiranthes sinensis (Pers.) Ames complex (Orchidaceae) in the Chinese Himalayas? Ecology and Evolution; DOI:I0.I002/ece3.4067

Tong ZY, Huang SQ (2016) Pre- and post-pollination interaction between six co-flowering Pedicularis species via heterospecific pollen transfer. New Phytologist 2I I:I452-I46I.

Tong ZY, Huang SQ (2018) Safe sites of pollen placement: a conflict of interest between plants and bees? Oecologia I86:163I7I.

Troscianko J, Stevens M (2015) Picture calibration and analysis toolbox - a free software suite for objectively measuring reflectance, colour and pattern. Methods in Ecology and Evolution 6:1320I33I.

Vasas V, Hanley D, Kevan PG, Chittka L (20I7) Multispectral images of flowers reveal the adaptive significance of using longwavelength-sensitive receptors for edge detection in bees. Journal of Comparative Physiology A 203:30I-3II.

Von Frisch K (1915) Der Farbensinn und Formensinn der Biene. Zoologische Jahrbücher Abteilung für allgemeine Zoologie und Physiologie 37:I-I87.

Vorobyev M, Kunze J, Gumbert A, Giurfa M, Menzel R (I997) Flowers through the insect eyes. Israel Journal of Plant Science 45:93-102.

Vorobyev M, Marshall J, Osorio D, Hempel de Ibarra N, Menzel R (1999) Colourful objects through animal eyes. Colour Research and Application 26: 2I4-2I7.

Wang H, Li DZ (2005) Pollination biology of four Pedicularis species (Scrophulariaceae) in northwestern Yunnan, China. Annals of the Missouri Botanical Garden 92:127-I38.

Weiss MR, Lamont BB (1997) Floral color change and insect pollination: A dynamic relationship. Israel Journal of Plant Science 45:185-200.

White TE, Dalrymple RL, Noble DWA, O'Hanlon JC, Zurek DB, Umbers KDL (2015) Reproducible research in the study of biological coloration. Animal Behaviour I06:5I-57.

Wikipedia (2. März 2017). CIE I93I color space. Accessed 9 March 2017 from Wikipedia: en.wikipedia.org/wiki/CIE_I93I_color_space

Williams S, Dyer A (2007) A photographic simulation of insect vision. The Journal of Ophthalmic Photography 29:I0-I4.

Williams P, Tang Y, Yao J, Cameron S (2009) The bumblebees of Sichuan (Hymenoptera: Apidae, Bombini). Systematics and Biodiversity 7:10I-189.

Wilmsen S, Gottlieb R, Junker RR, Lunau K (2017) Bumblebees require visual pollen stimuli to initiate and multimodal stimuli to complete a full behavioral sequence in close-range flower orientation. Ecology and Evolution 7:1384-1393.

Winter Y, Lopez J, von Helversen O (2003) Ultraviolet vision in a bat. Nature 425:612-614

Wu ZY, Raven PH, Hong DY (2013) Flora of China Vol. I: Introduction. Science Press, Beijing, China and Missouri Botanical Garden Press, St. Louis, USA. 
Yan J, Wang G, Sui Y, Wang ML, Zhang L (2016) Pollinator responses to floral colour change, nectar, and scent promote reproductive fitness in Quisqualis indica(Combretaceae). Scientific Reports 6:24408.

Yan J, Wang ML, Zhang L (2018) Light induces petal color change in Quisqualis indica (Combretaceae). Plant Diversity 40:28-34.

Yang HB, Holmgren NH, Mill RR (1998) Pedicularis. In: Wu ZY, Raven PH, Hong DY (20I3) Flora of China, Vol I8: Science
Press, Beijing, China and Missouri Botanical Garden Press, St. Louis, USA.

Zhang C, Vereecken NJ, Wang LL, Tian B, Dafni A, Yang YP, Duan YW (2017) Are nectar guide colour changes a reliable signal to pollinators that enhances reproductive success? Plant Ecology \& Diversity 10:89-96. 